\title{
Murdock, Nebraska, Groundwater \\ Flow and Transport Modeling in Support of Long-Term Monitoring
}

prepared by

Environmental Research Division

Argonne National Laboratory 


\begin{abstract}
About Argonne National Laboratory
Argonne is managed by The University of Chicago for the U.S. Department of Energy under contract W-31-109-Eng-38. The Laboratory's main facility is outside Chicago, at 9700 South Cass Avenue, Argonne, Illinois 60439. For information about Argonne and its pioneering science and technology programs, see www.anl.gov.
\end{abstract}

\title{
Availability of This Report
}

This report is available, at no cost, at http://www.osti.gov/bridge. It is also available on paper to U.S. Department of Energy and its contractors, for a processing fee, from:

U.S. Department of Energy

Office of Scientific and Technical Information

P.O. Box 62

Oak Ridge, TN 37831-0062

phone (865) 576-8401

fax (865) 576-5728

reports@adonis.osti.gov

\section{Disclaimer}

This report was prepared as an account of work sponsored by an agency of the United States Government. Reference herein to any specific commercial product, process, or service by trade name, trademark, manufacturer, or otherwise, does not necessarily constitute or imply its endorsement, recommendation, or favoring by the United States Government or any agency thereof.

The views and opinions of document authors expressed herein do not necessarily state or reflect those of the United States Government or any agency thereof, Argonne National Laboratory, or The University of Chicago. 


\section{Murdock, Nebraska, Groundwater Flow and Transport Modeling in Support of Long-Term Monitoring}

by

Applied Geosciences and Environmental Management Section

Environmental Research Division, Argonne National Laboratory

January 2003 

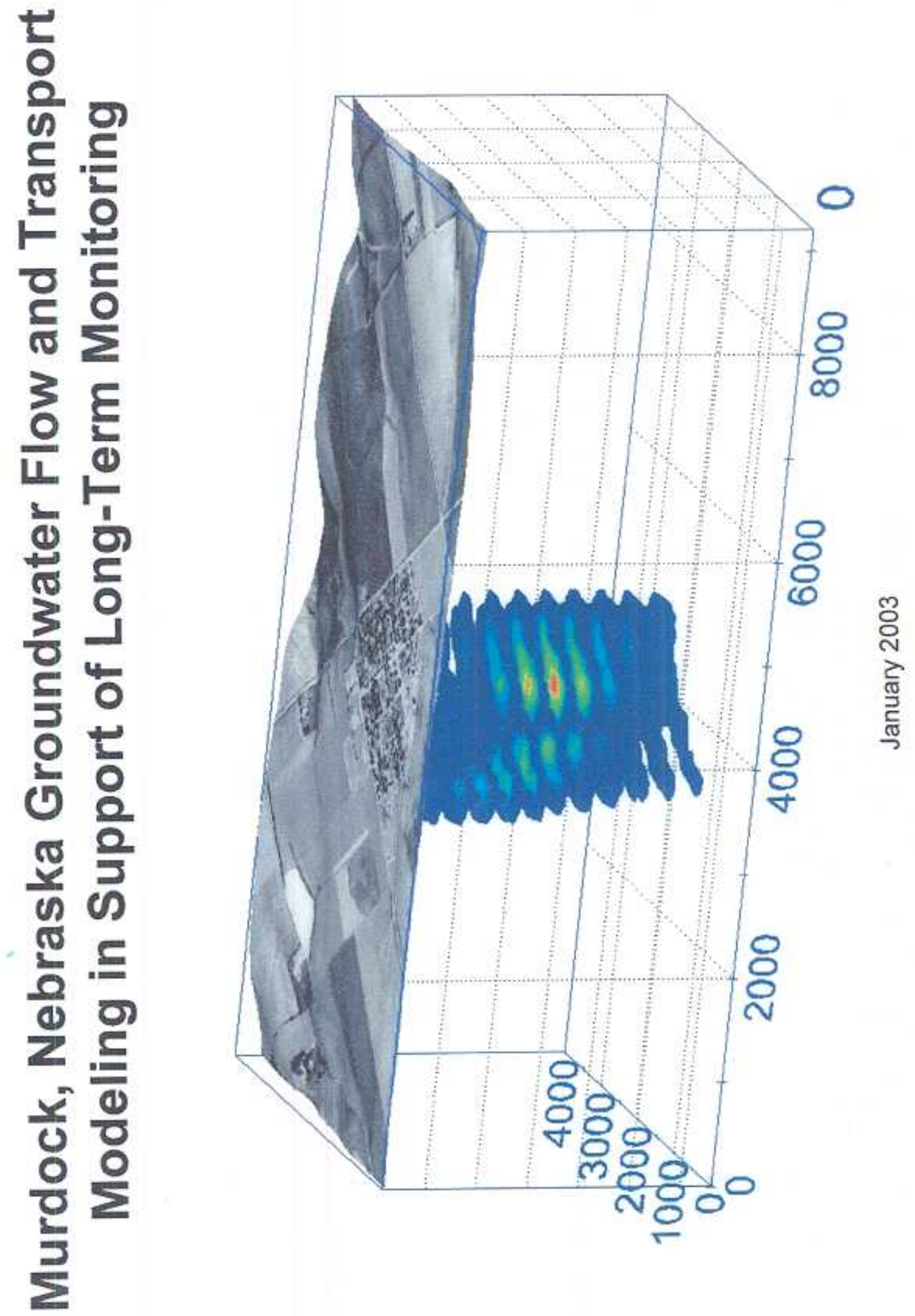


\section{MURDOCK, NEBRASKA GROUNDWATER FLOW AND TRANSPORT MODELING \\ AND \\ LONG-TERM GROUNDWATER QUALITY MONITORING RECOMMENDATIONS}

\section{Fall 2002 Assignments}

- Update all models to MODFLOW-2000

- Re-calibrate original Murdock steady-state groundwater flow model to November 25, 1998 observed water levels (Phase 1 Hydrology)

- Determine time when climatologic/hydrologic regime changed in eastern Nebraska. Groundwater levels observed in 2002 are significantly lower than all values observed previously (1997-1999). Palmer Hydrologic Drought Index

- Determine appropriate groundwater level data for calibration of new (Phase 2)

groundwater flow model representing current hydrologic regime (avg. of 2002 observations)

- $\mathrm{Re}$-evaluate/recalculate initial $\mathrm{CCl}_{4}$ concentrations for MT3D-99 solute transport model calibration - 1996/97 concentration data. Too much $\mathrm{CCl}_{4}$ mass in eastern portions of original transport model

- Re-calibrate Murdock MT3D-99 solute transport model to November 1999 observed concentrations using revised initial 1996/97 concentrations

- Include historical average concentrations at S2 as a constant concentration in transport model

- With re-calibrated solute transport model simulate $\mathrm{CCl}_{4}$ dissolved phase transport from December 12, 1996 to December 31, 1999 with Phase 1 groundwater flow model.

- Simulate $\mathrm{CCl}_{4}$ solute transport from January 1,2000 to December 12,2012 with Phase 2 groundwater flow model and $\mathrm{CCl}_{4}$ initial conditions set at December 31, 1999 simulated values (i.e., Phase 1 model ending concentrations)

- Plot simulated $\mathrm{CCl}_{4}$ concentration time series for all trigger action wells, and non-trigger action wells monitored during 2002 for all layers inclusive in each well screened interval

- Set the trigger action level to the maximum simulated screen interval concentration for each trigger action well

- Present results (graphs/tables - but no written report) end of January 2003 


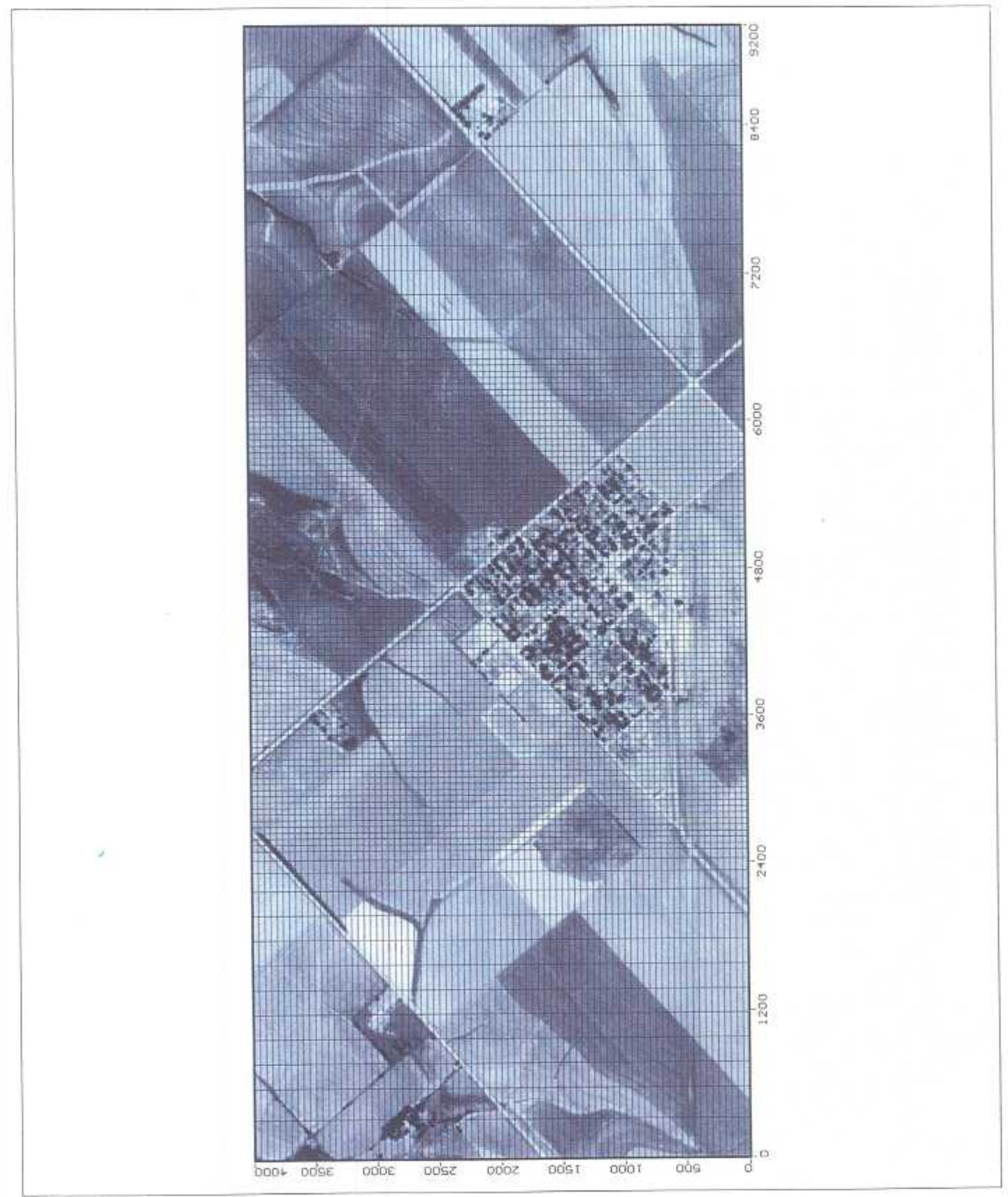




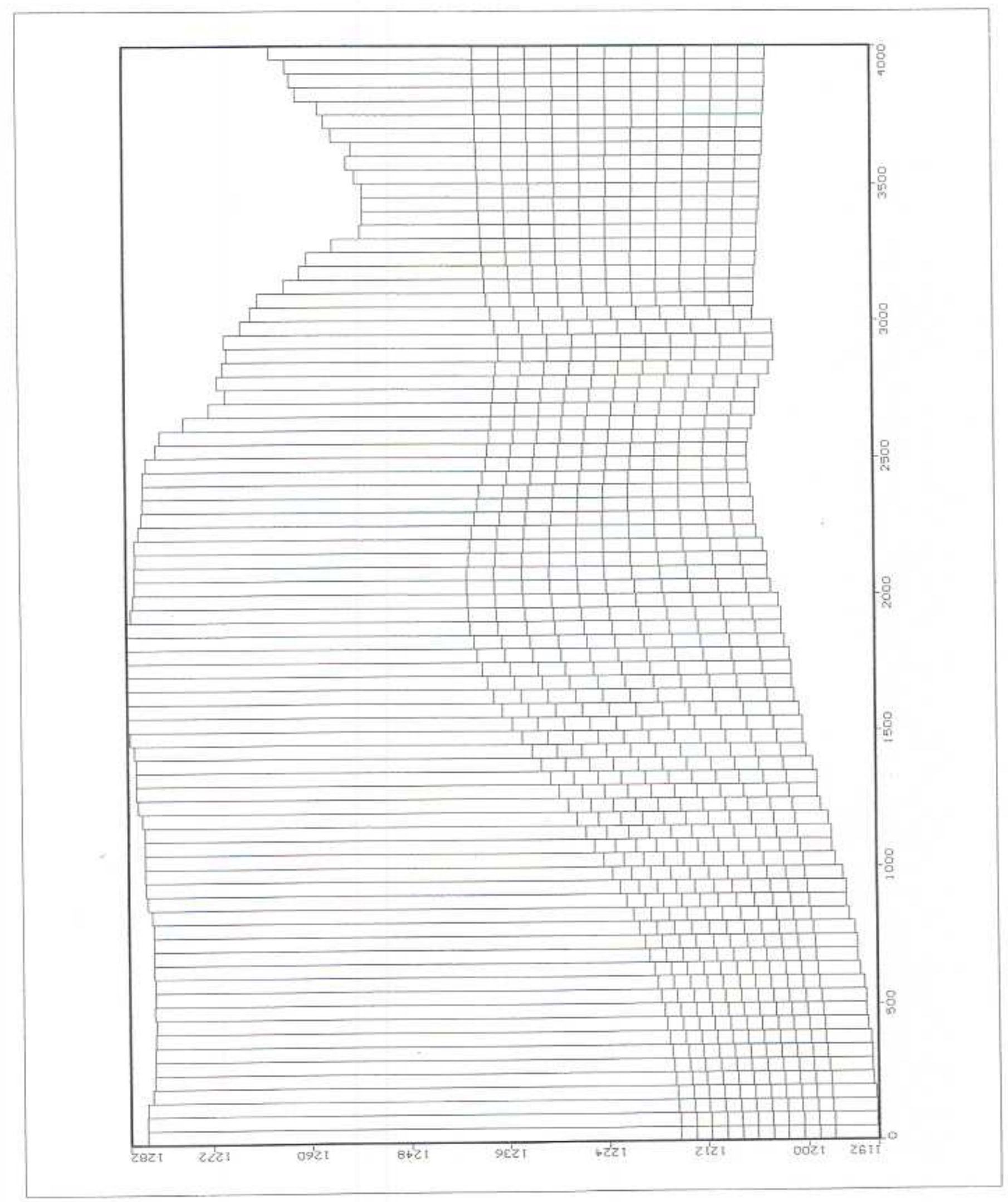




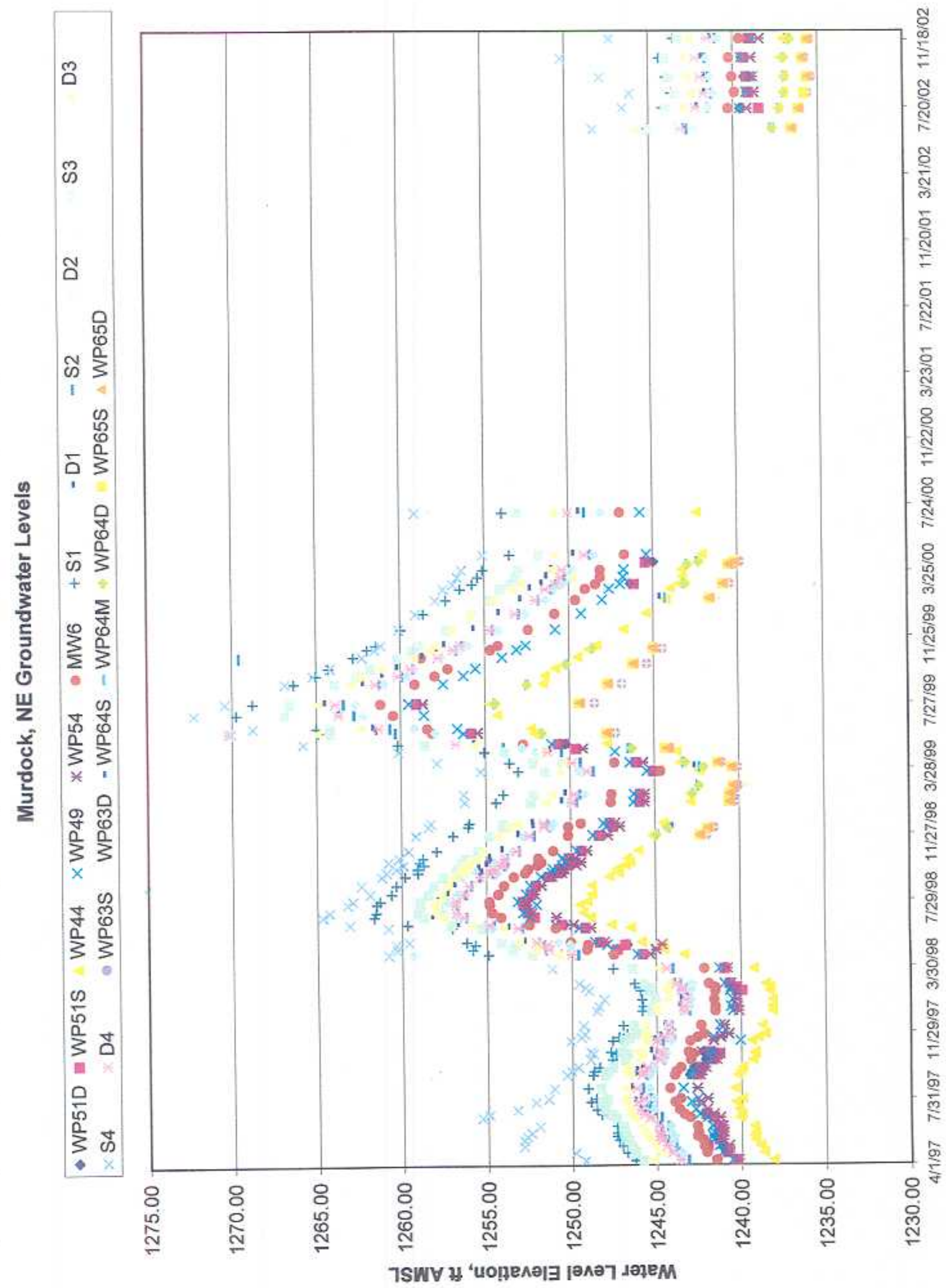




\section{Calculated vs. Observed Head : Steady state}

Calibration to November 25, 1998

groundwater water levels (original modeling)

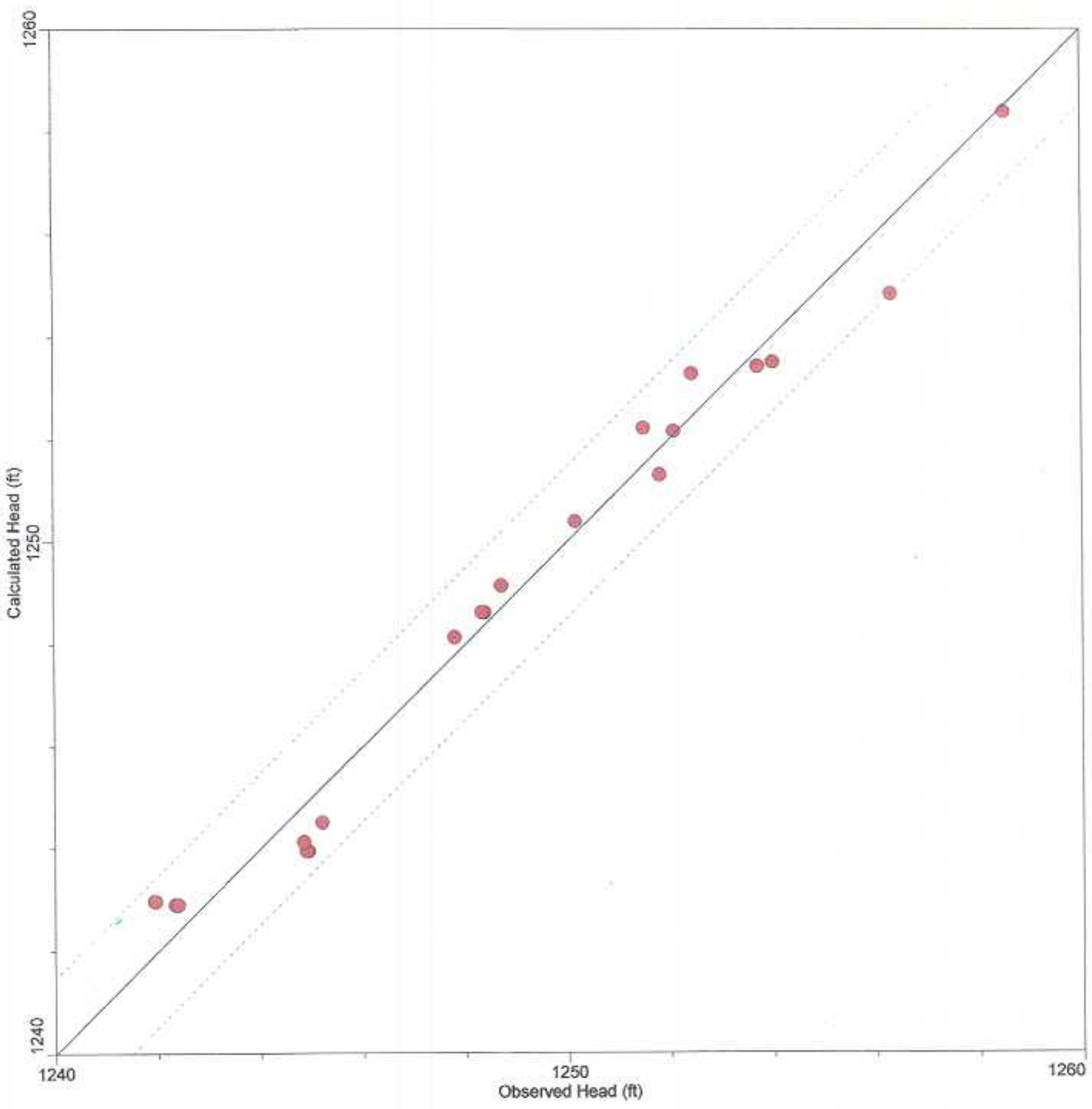




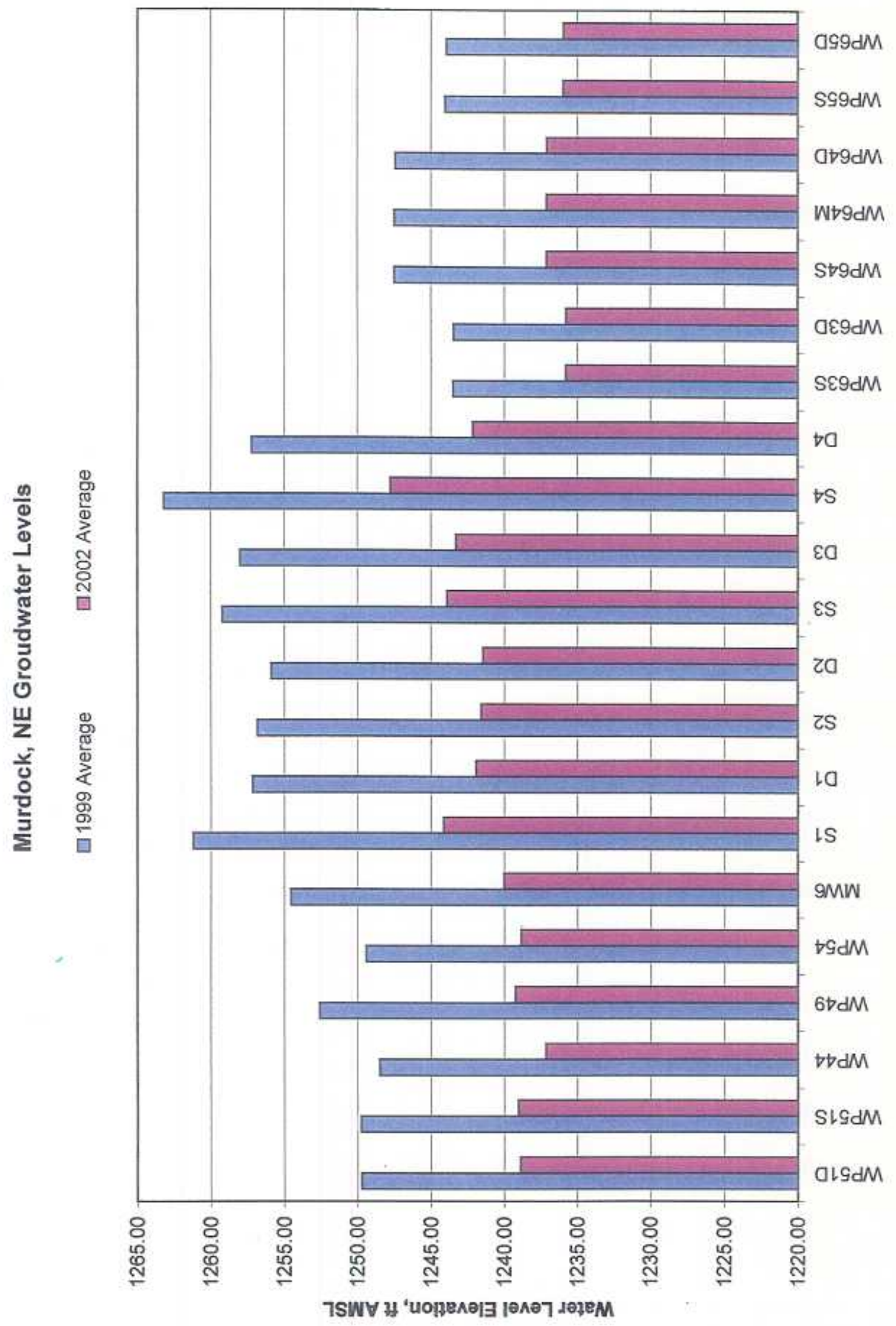


Agricultural Divisions in Nebraska - Murdock is in Division 6

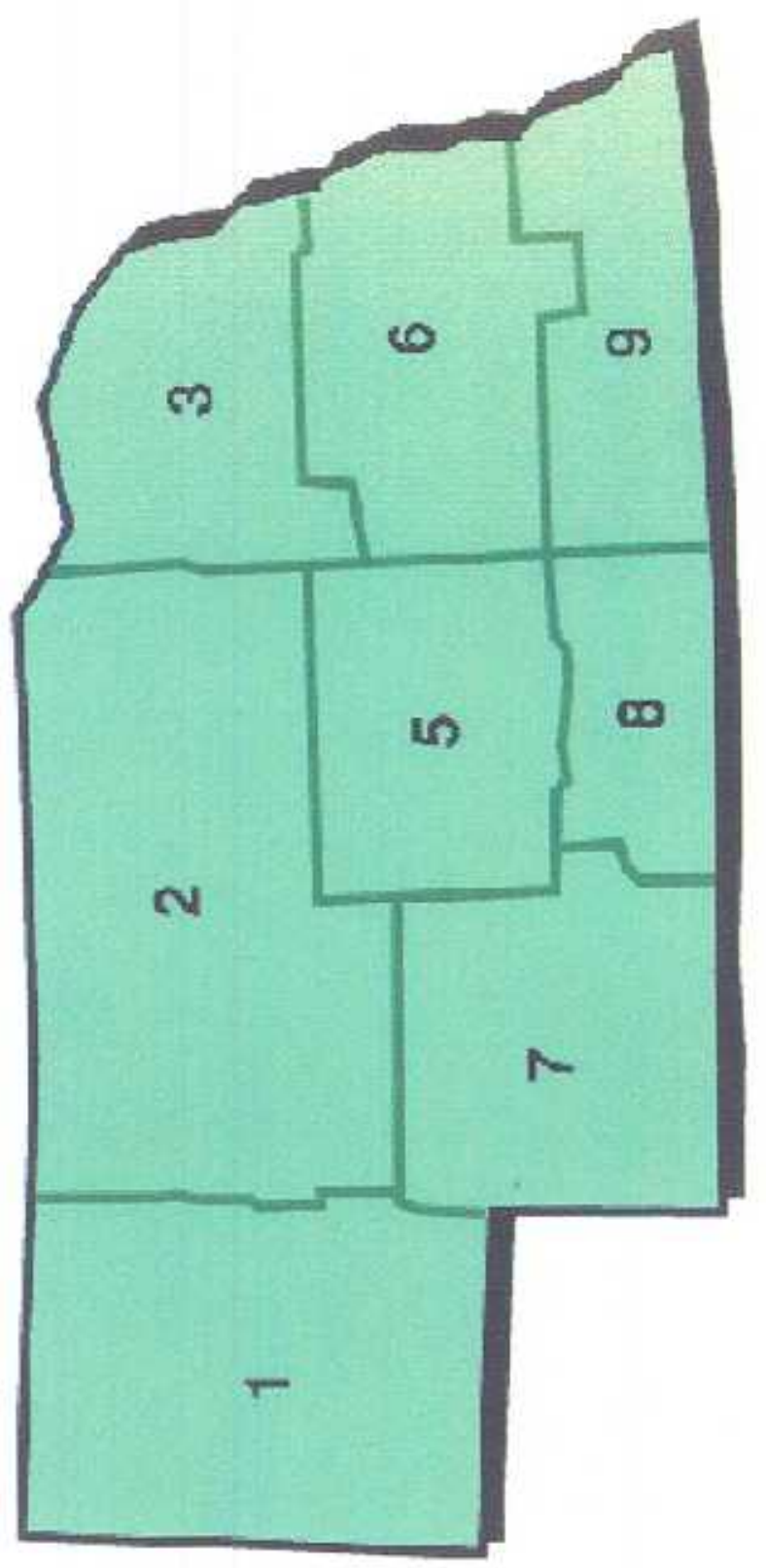



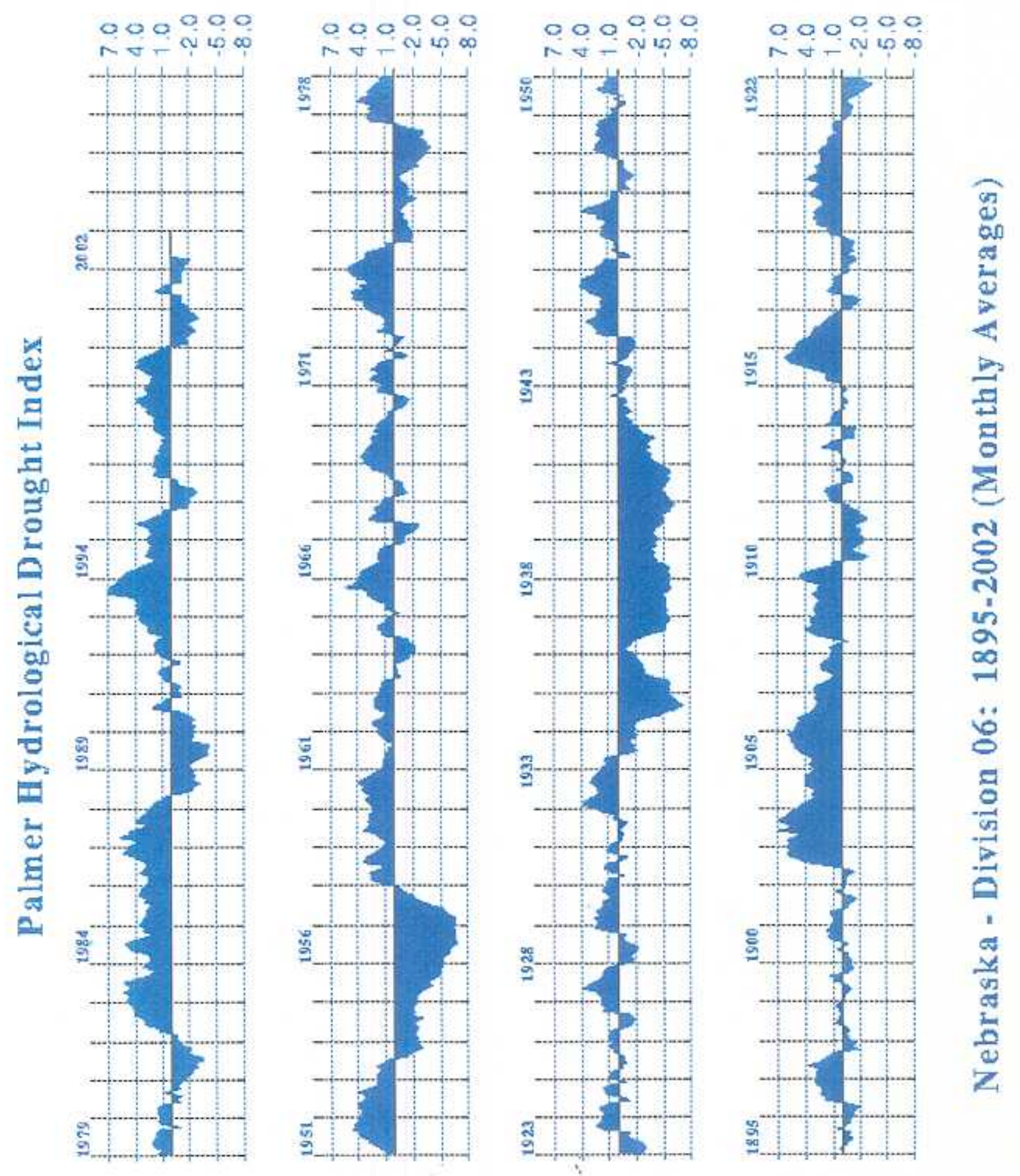


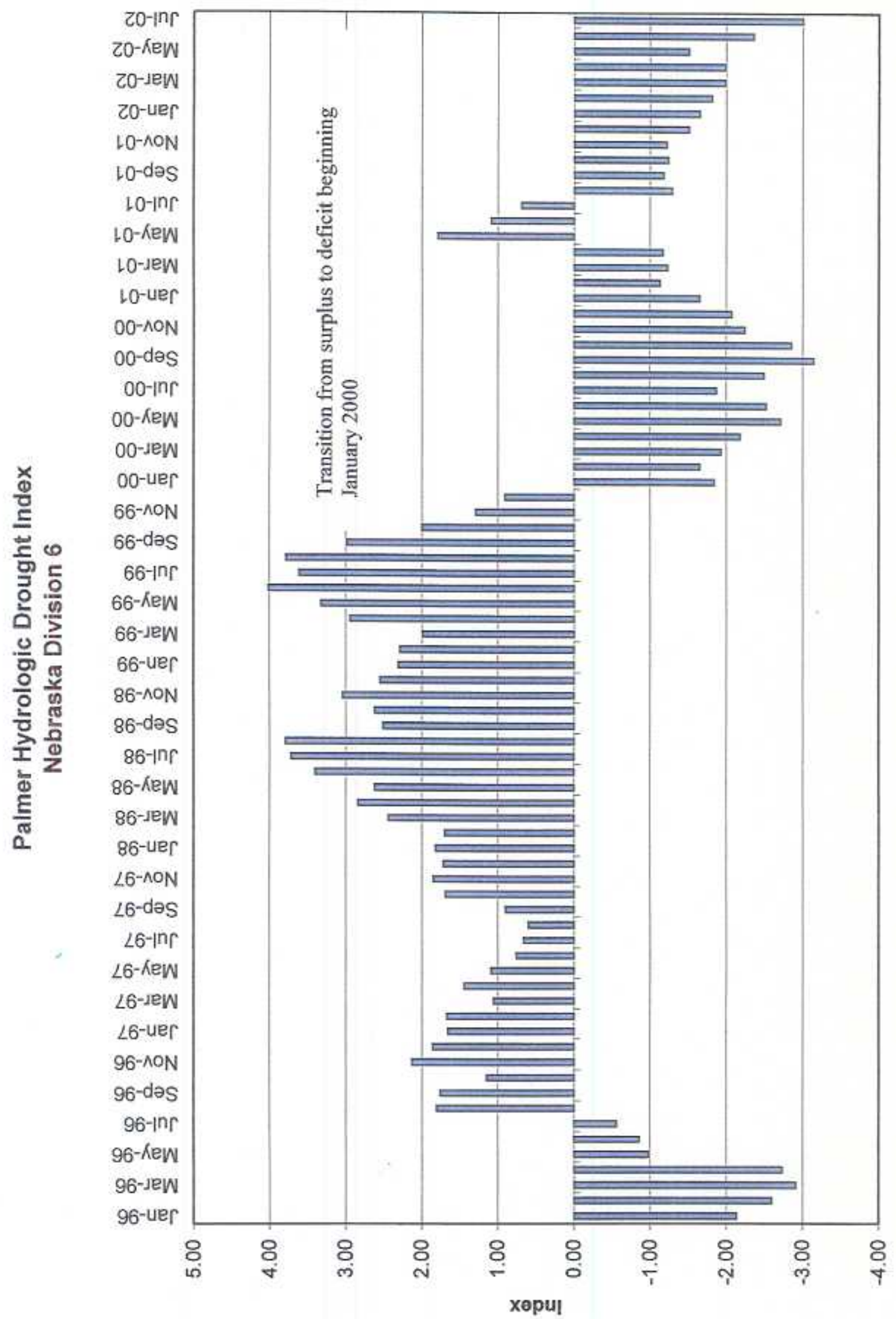




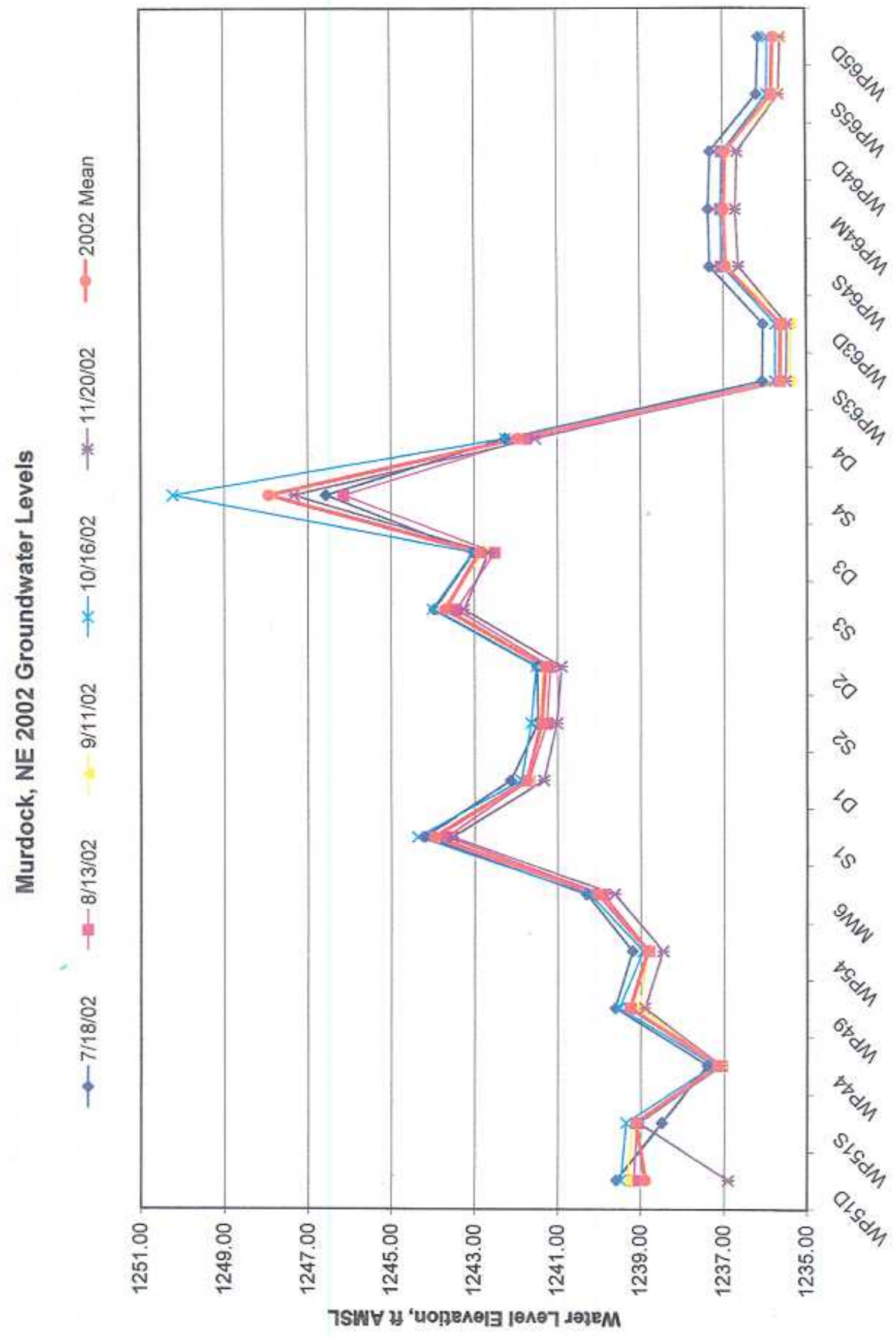


Calculated vs. Observed Head : Steady state

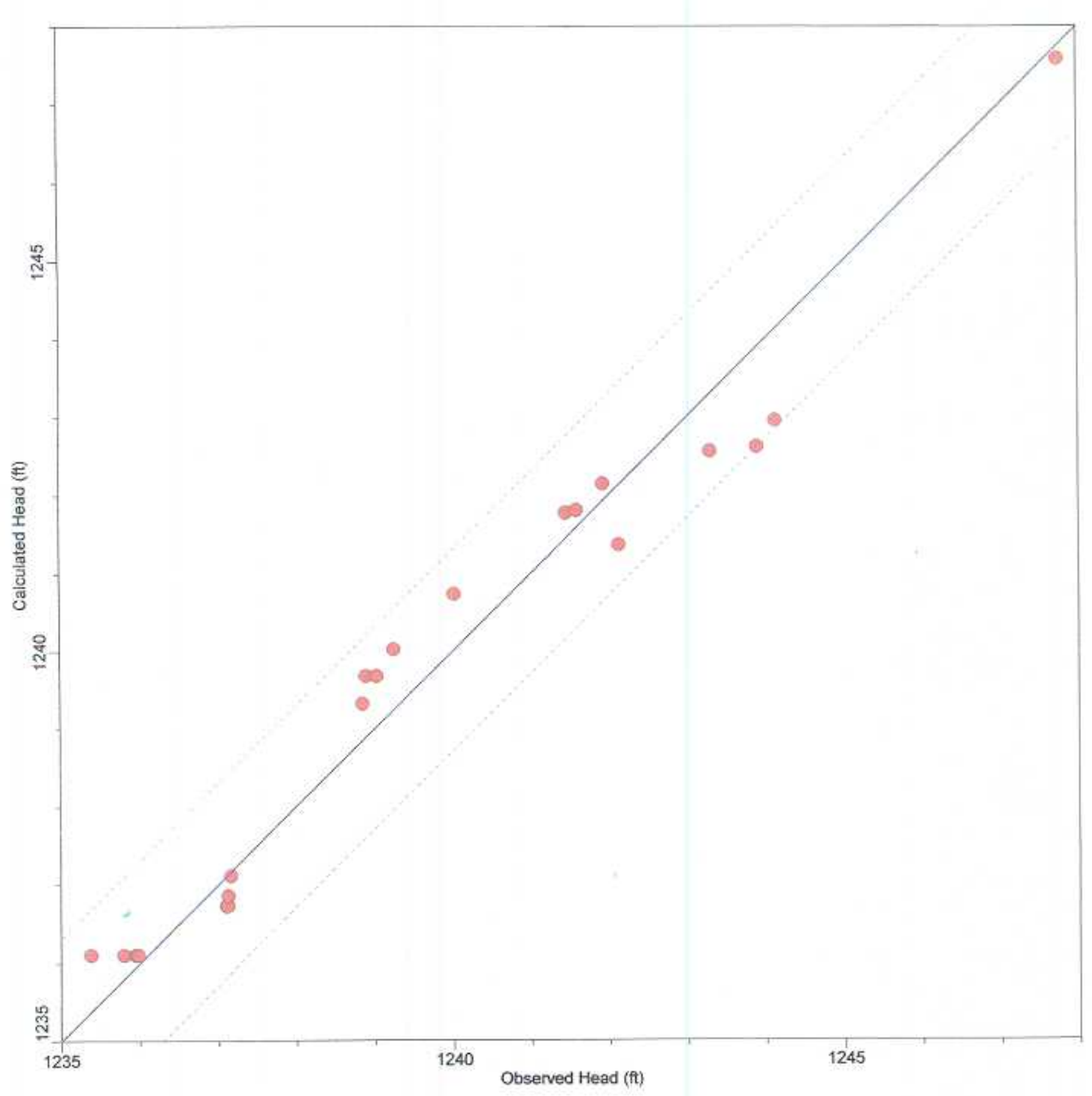

Calibration to average observed 2002

groundwater levels

Num.Points : 21

Max. Residual: -1.27854 (ft) at S3/S3

Min. Residual: -0.04317871 (ft) at WP44MP44

Residual Mean : $0.01155576(\mathrm{ft})$

Absolute Residual Mean : 0.5081736 (ft) 
Initial $\mathrm{CCl}_{4}$ concentration distribution for transport model calibration

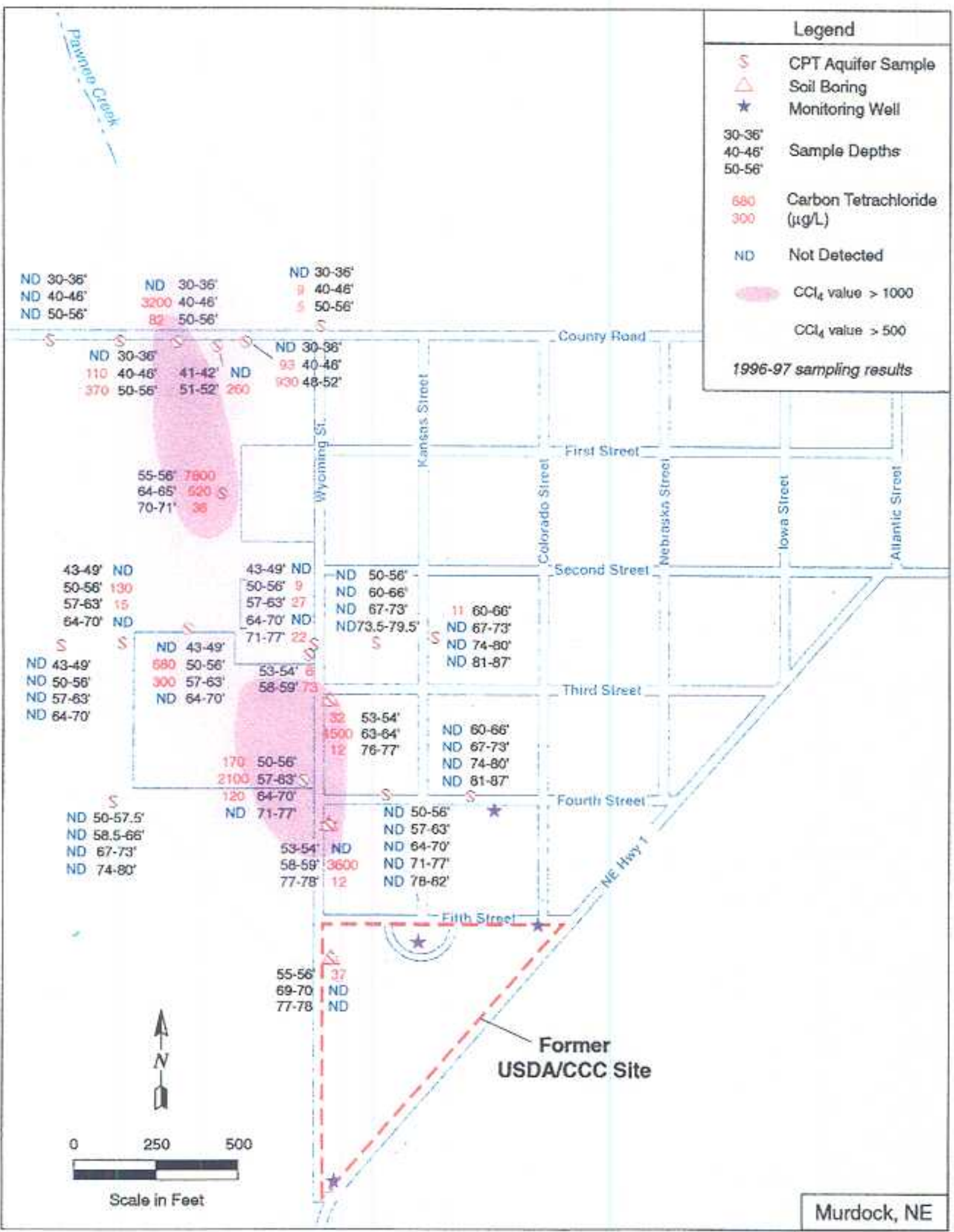




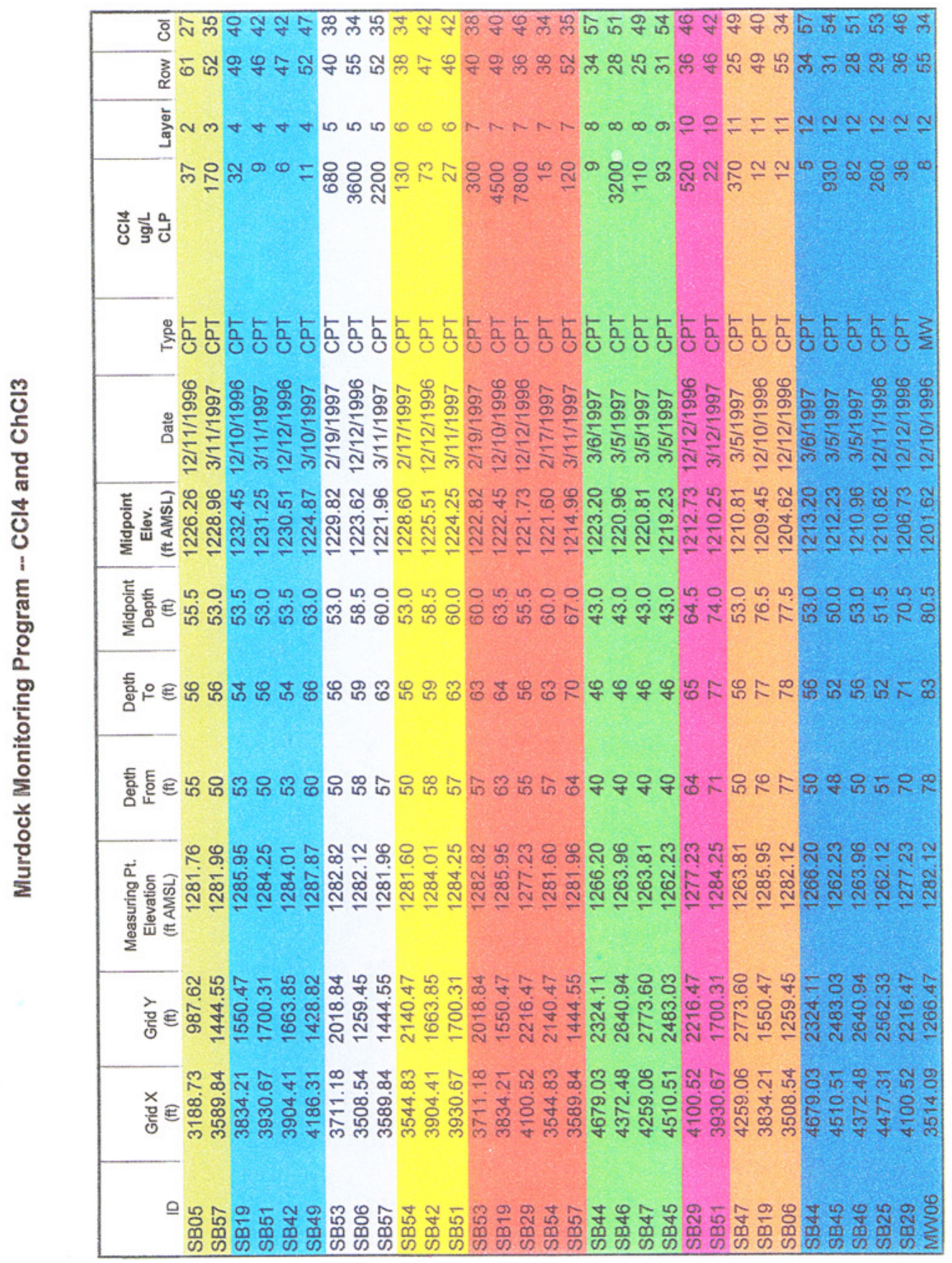


Murdock groundwater model layer structure

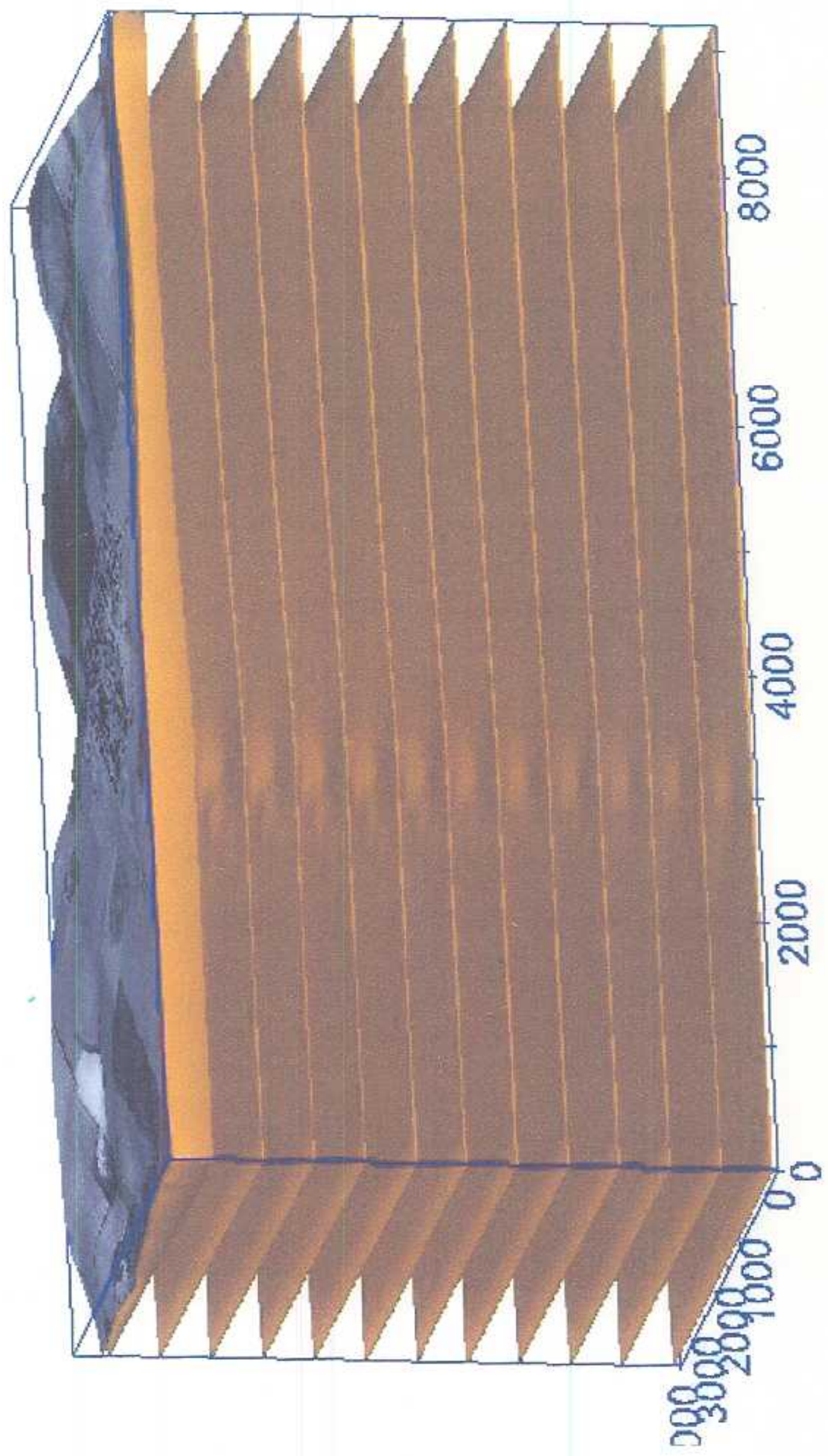


Initial $\mathrm{CCl}_{4}$ concentrations for MT3D-99

transport modeling by model layer

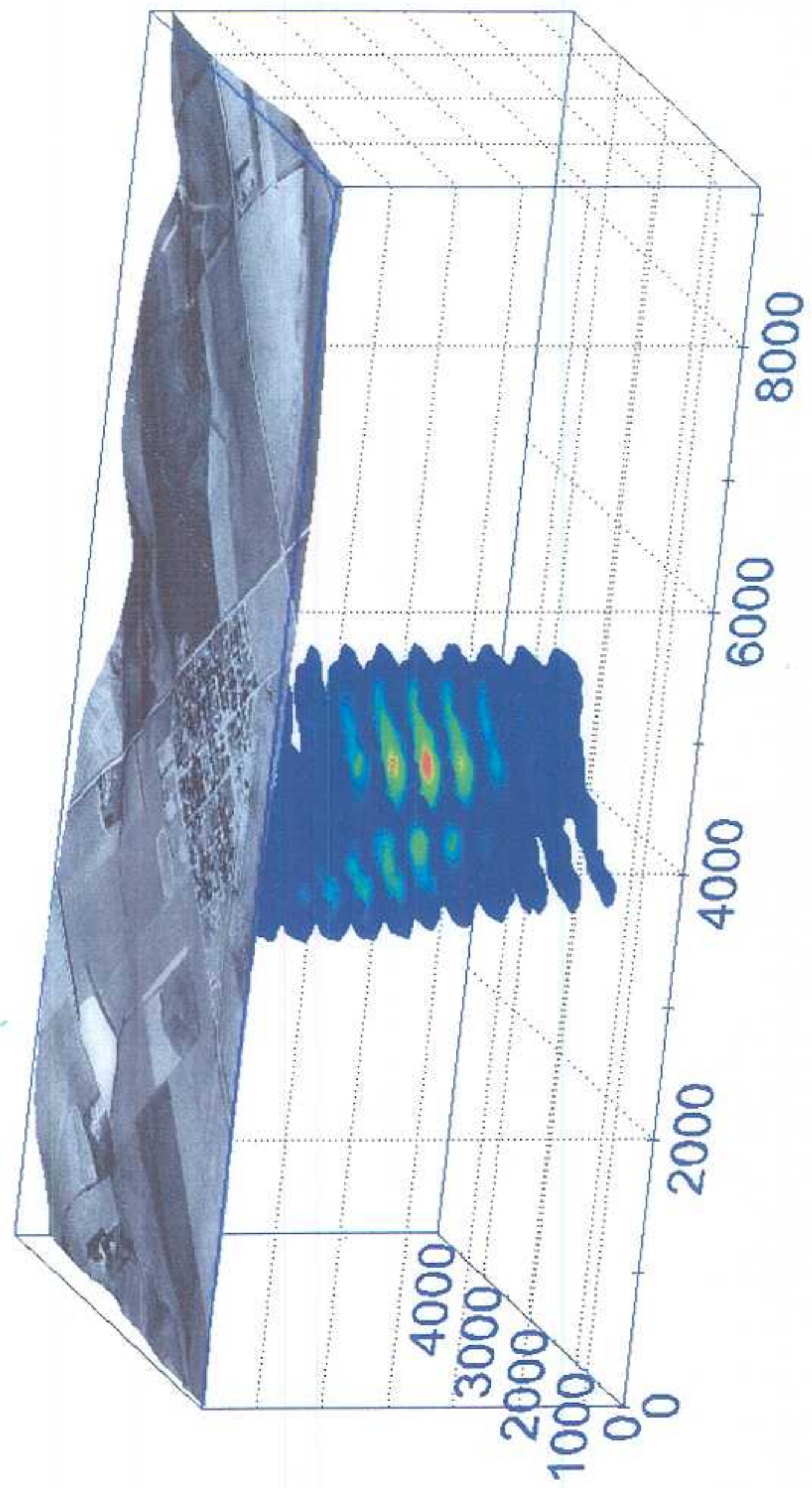




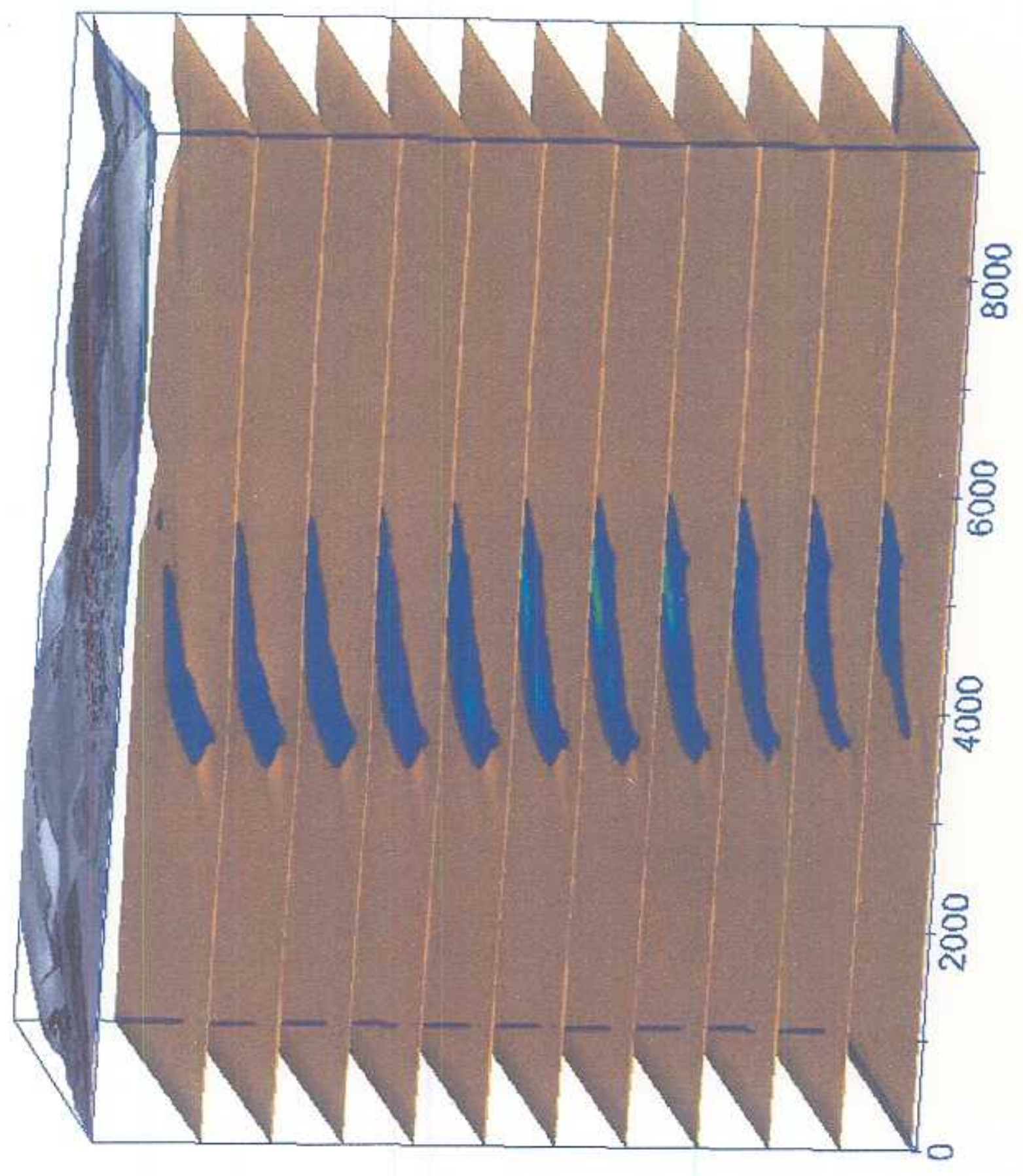


November 1999 transport model calibration target concentrations

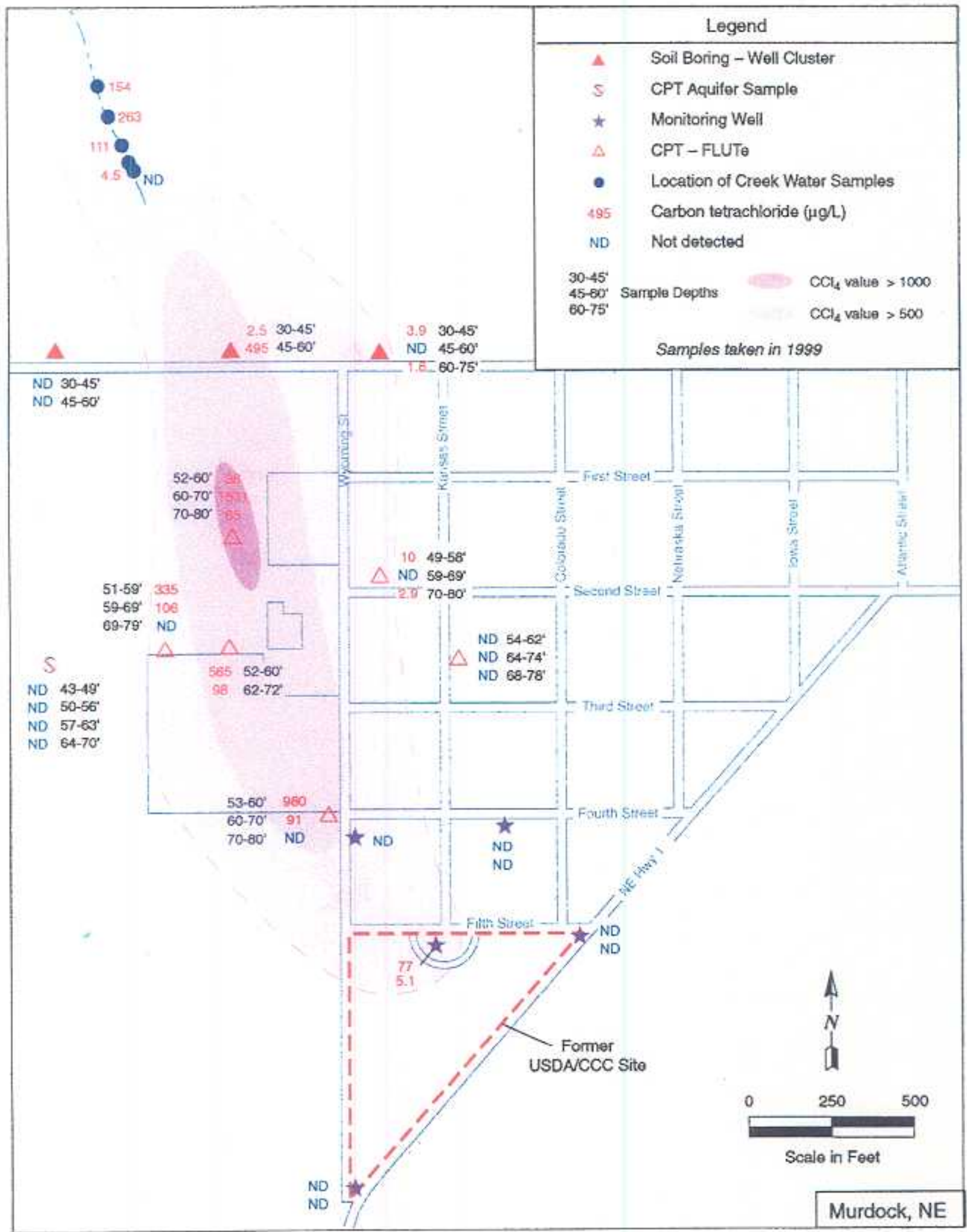




\section{Calculated vs. Observed Concentration : Time $=1056$ days}

CCl4 [Extrapolated Observed] $\odot \quad$ CCl4 [interpolated Observed] $-95 \%$ confidence interval
$-95 \%$ interval

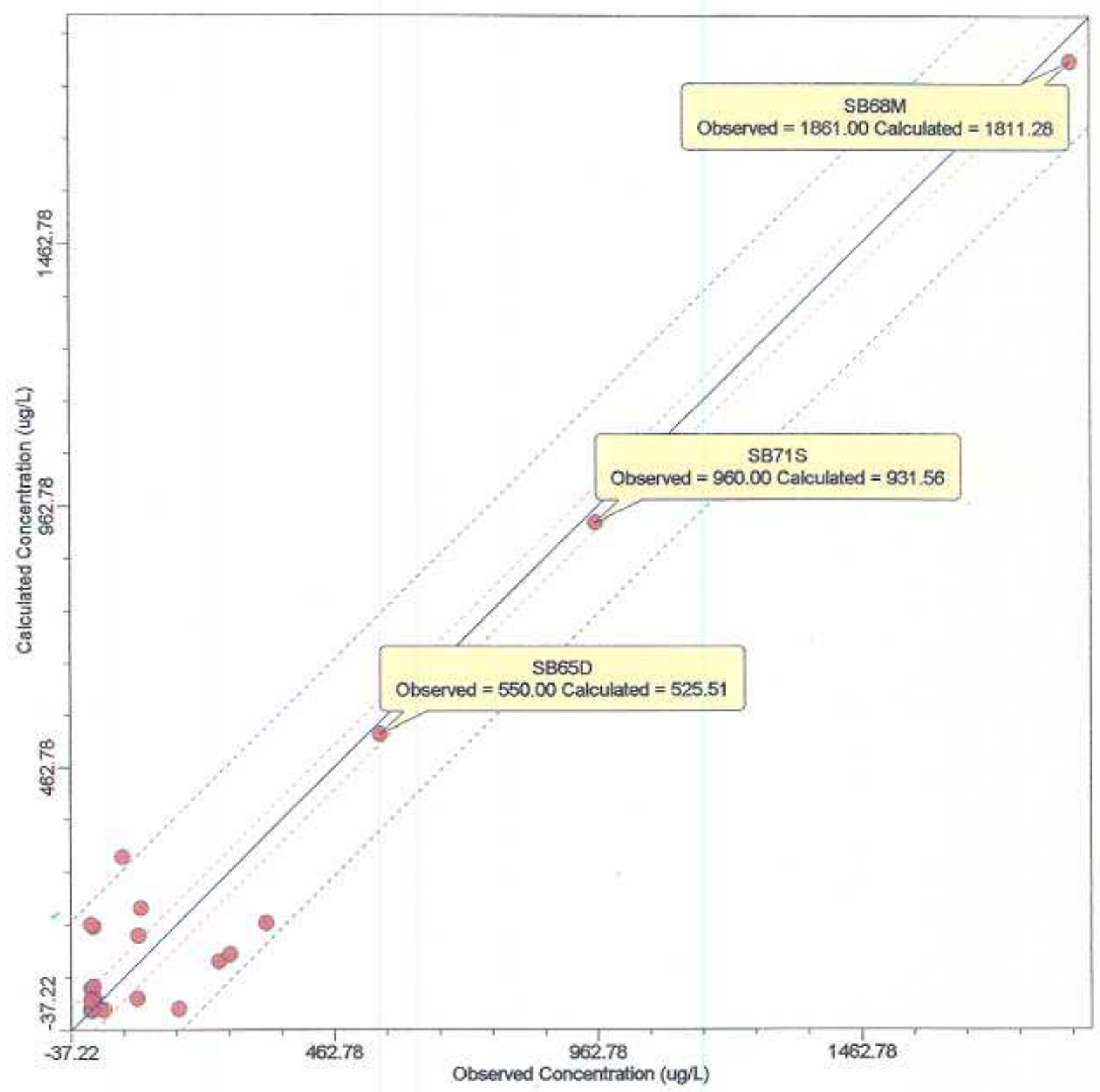

Num. Points : 24

Max. Residual: 230.3179 (ug/L) at SB71MSB71M

Min. Residual: 0.07512894 (ug/L) at SB63S/SB63S

Standard Emor of the Estimate : 20.49186 (ug/L)

Residual Mean : -0.5727512 (ug/L)

Absolute Residual Mean : 69.42724 (ug/L)

Root mean squared : $98.27717(\mathrm{ug} / \mathrm{L})$ Normalized RMS : 5.280879 (\%) 


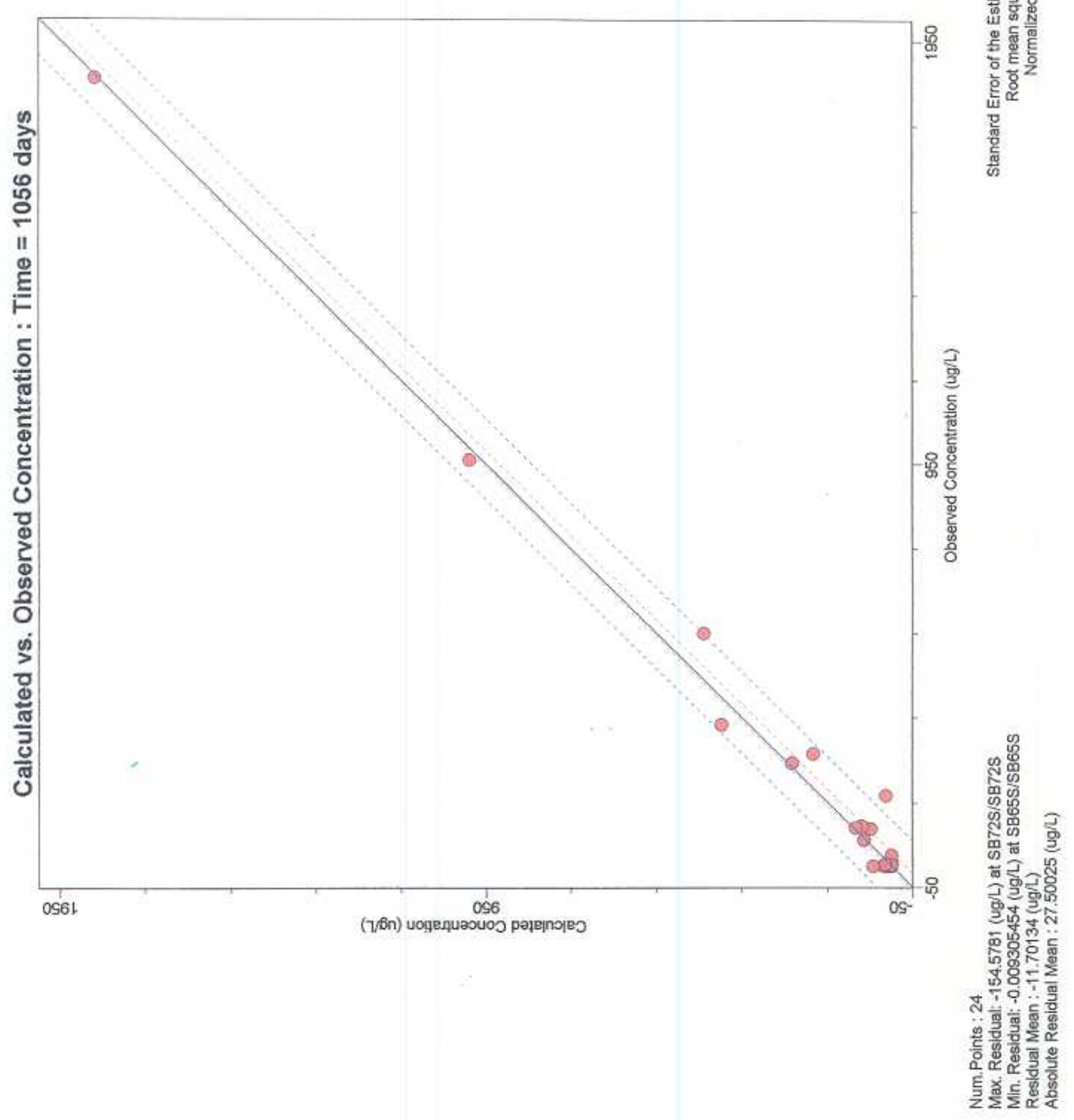




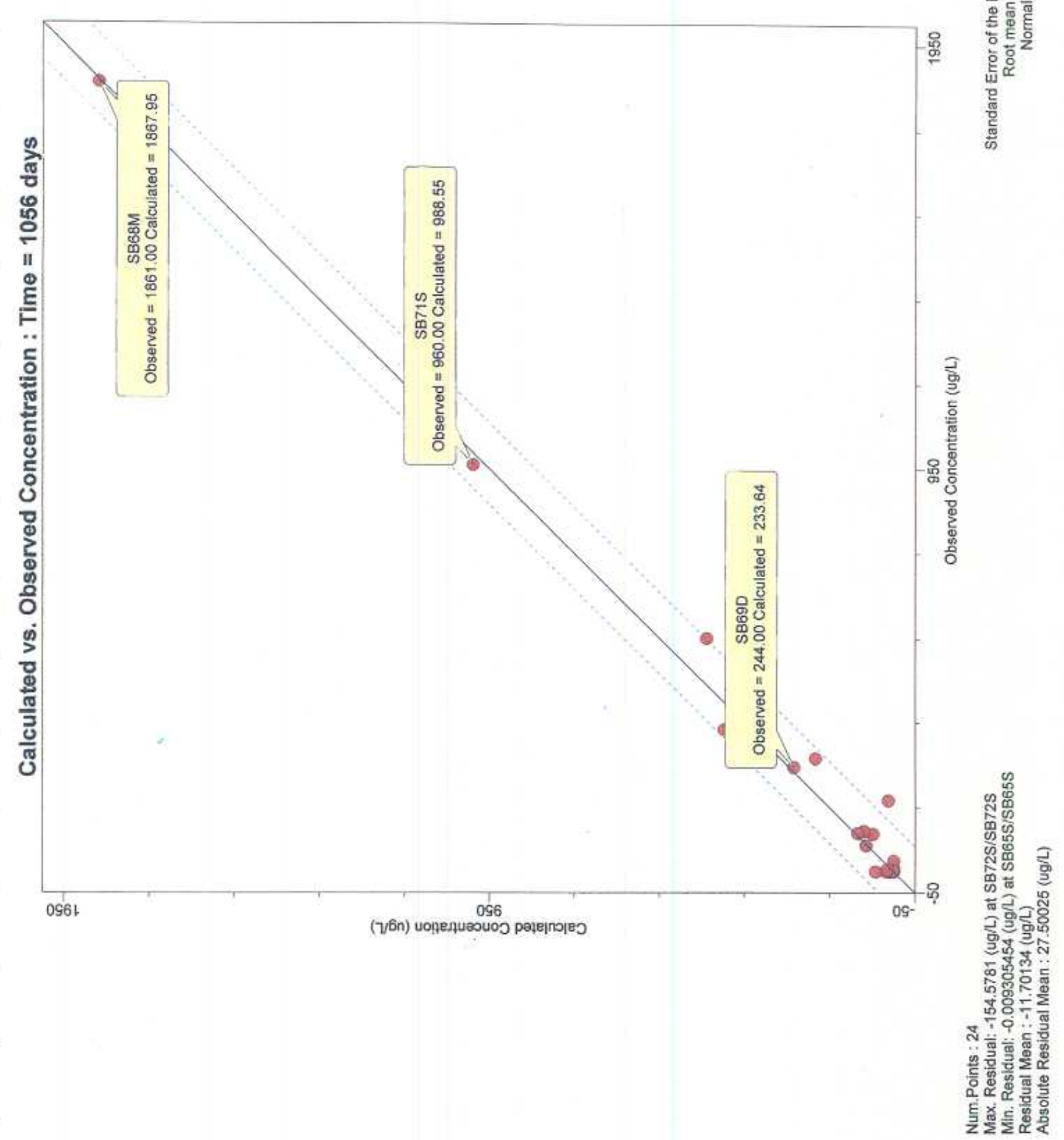




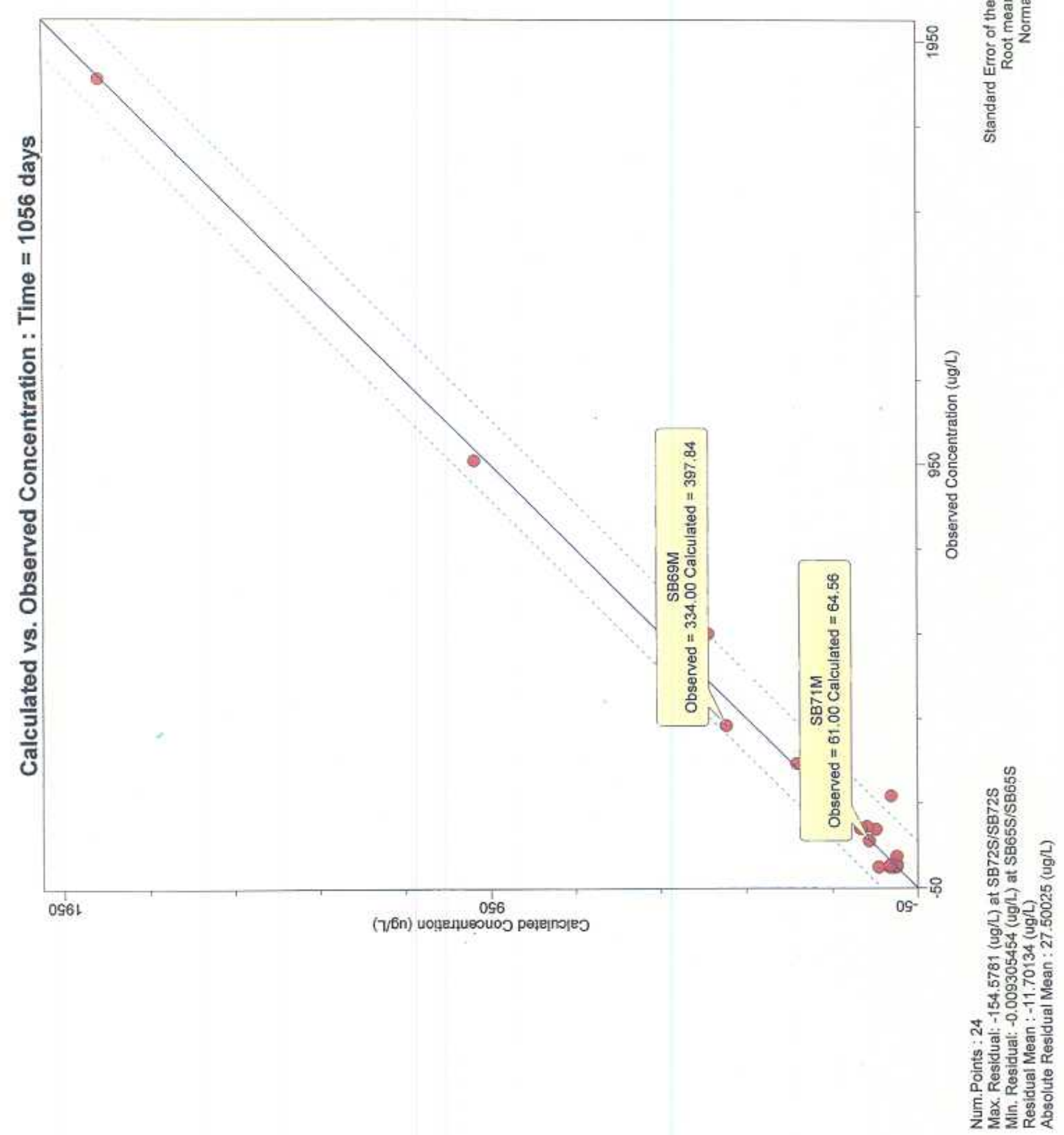



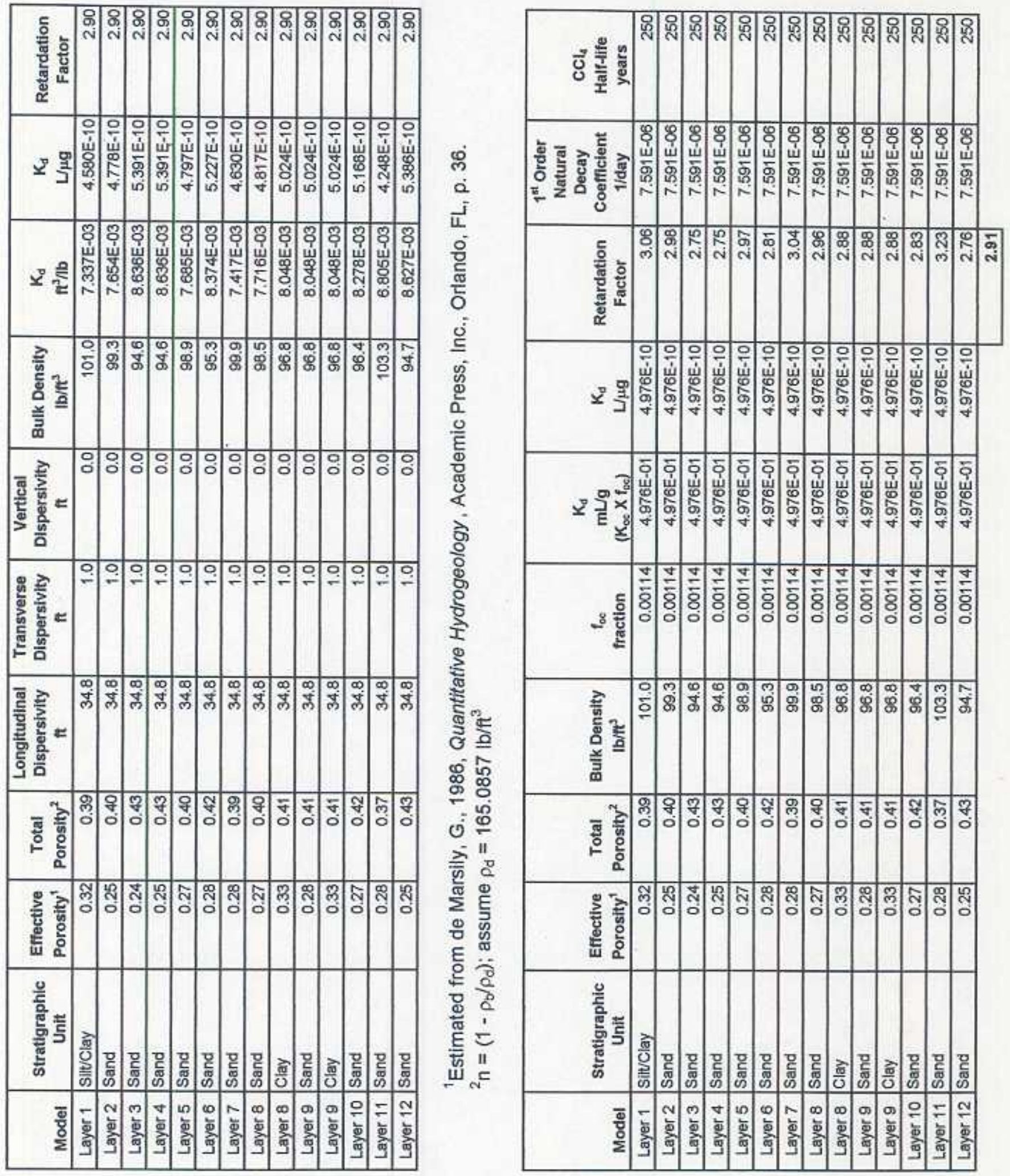


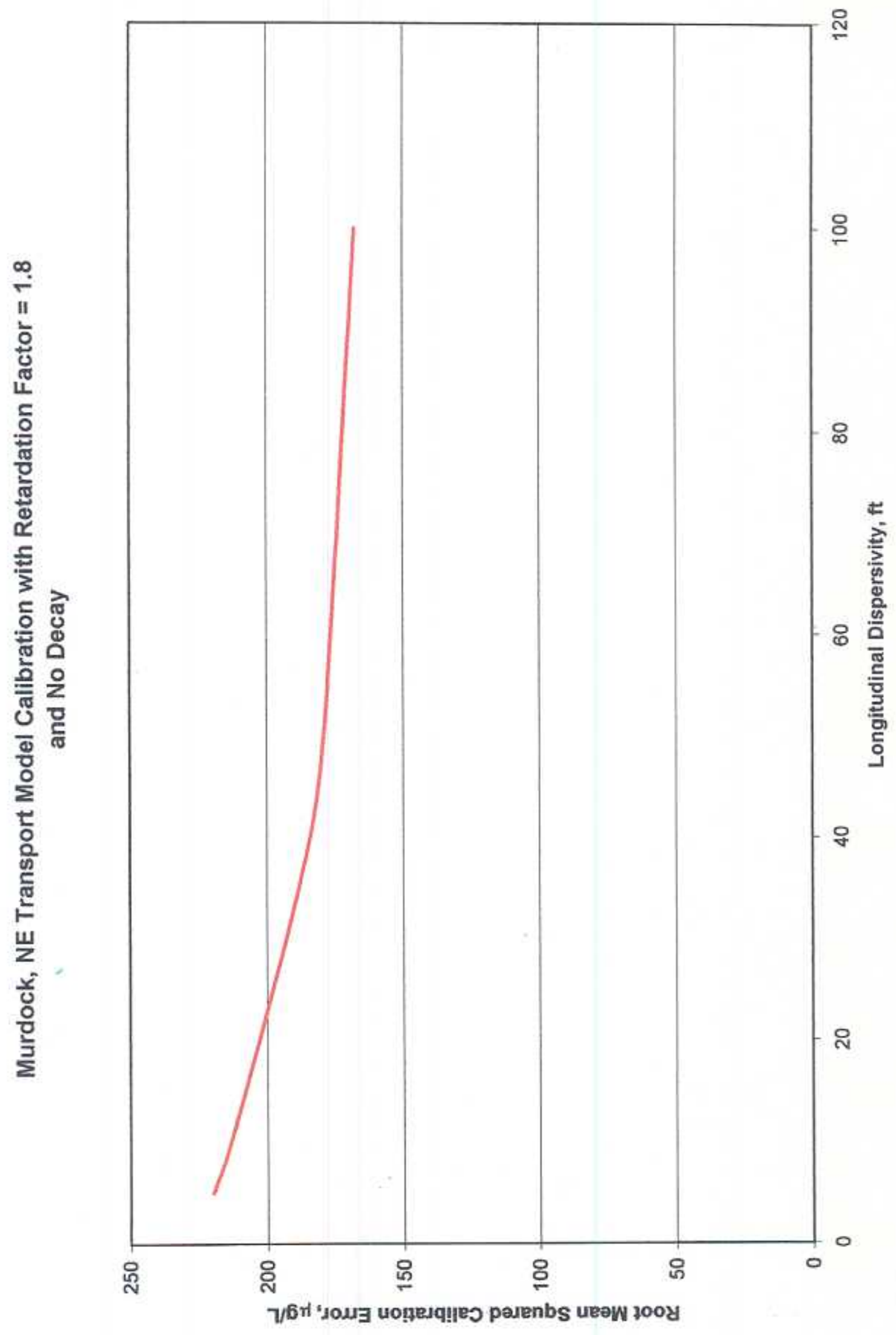




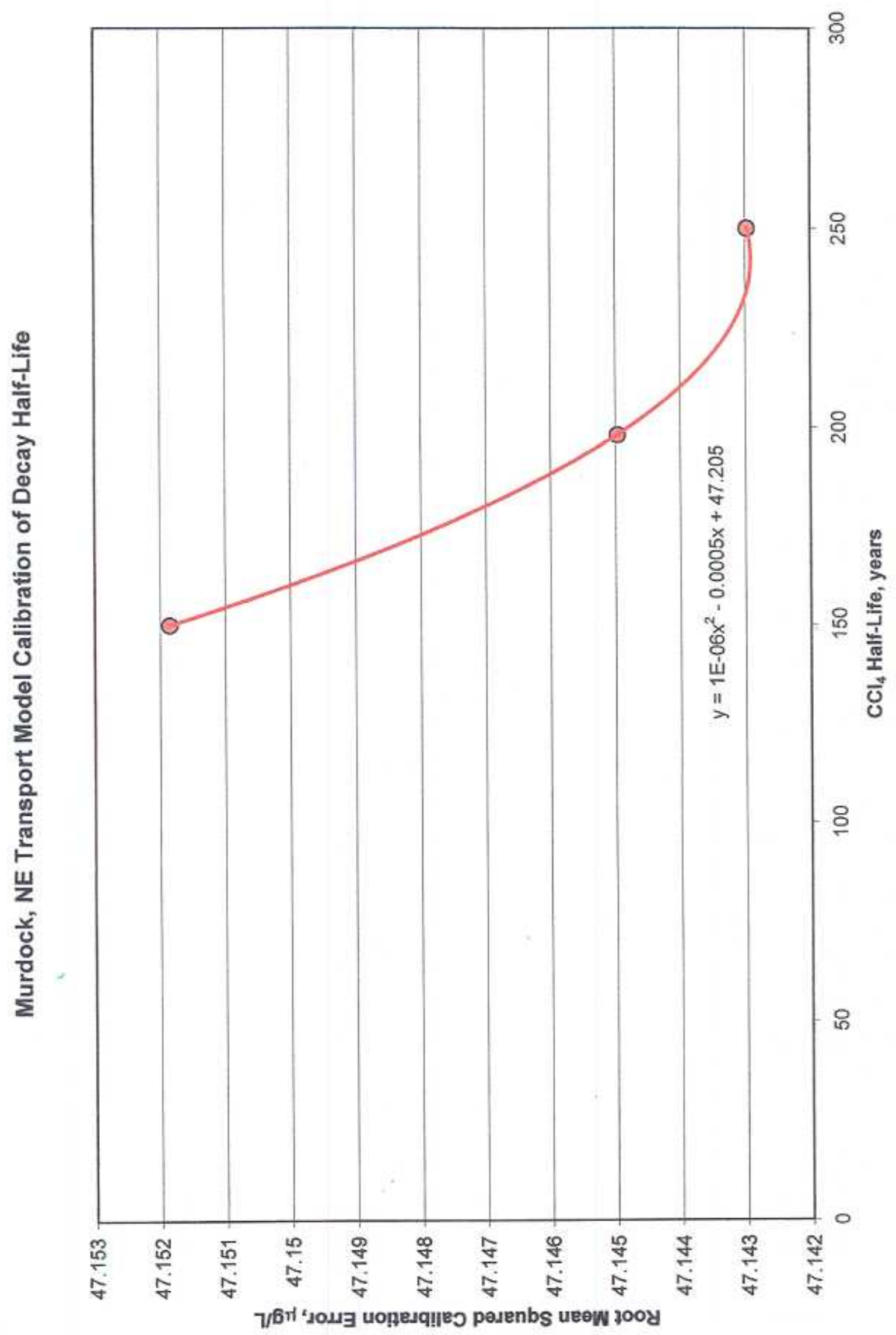




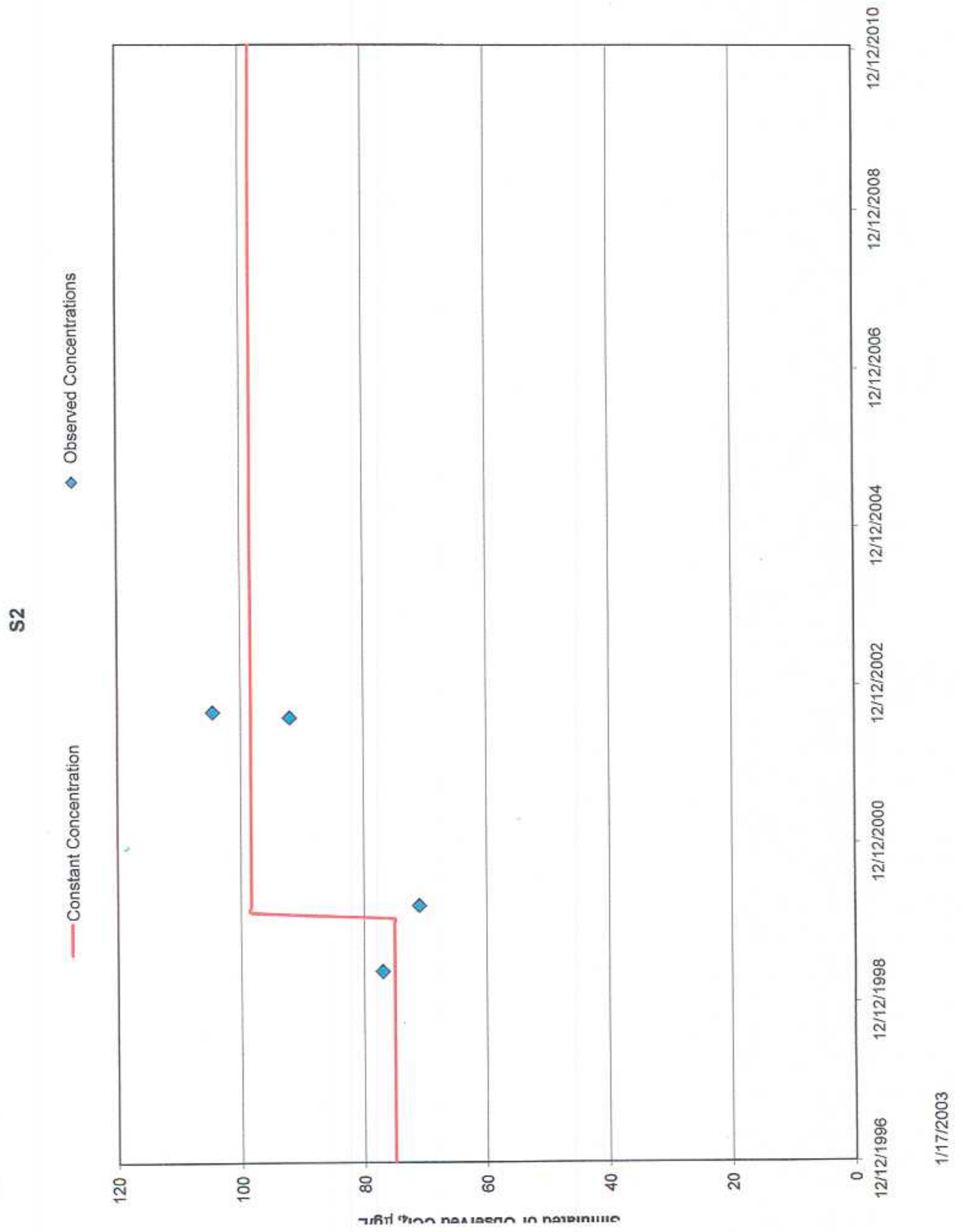



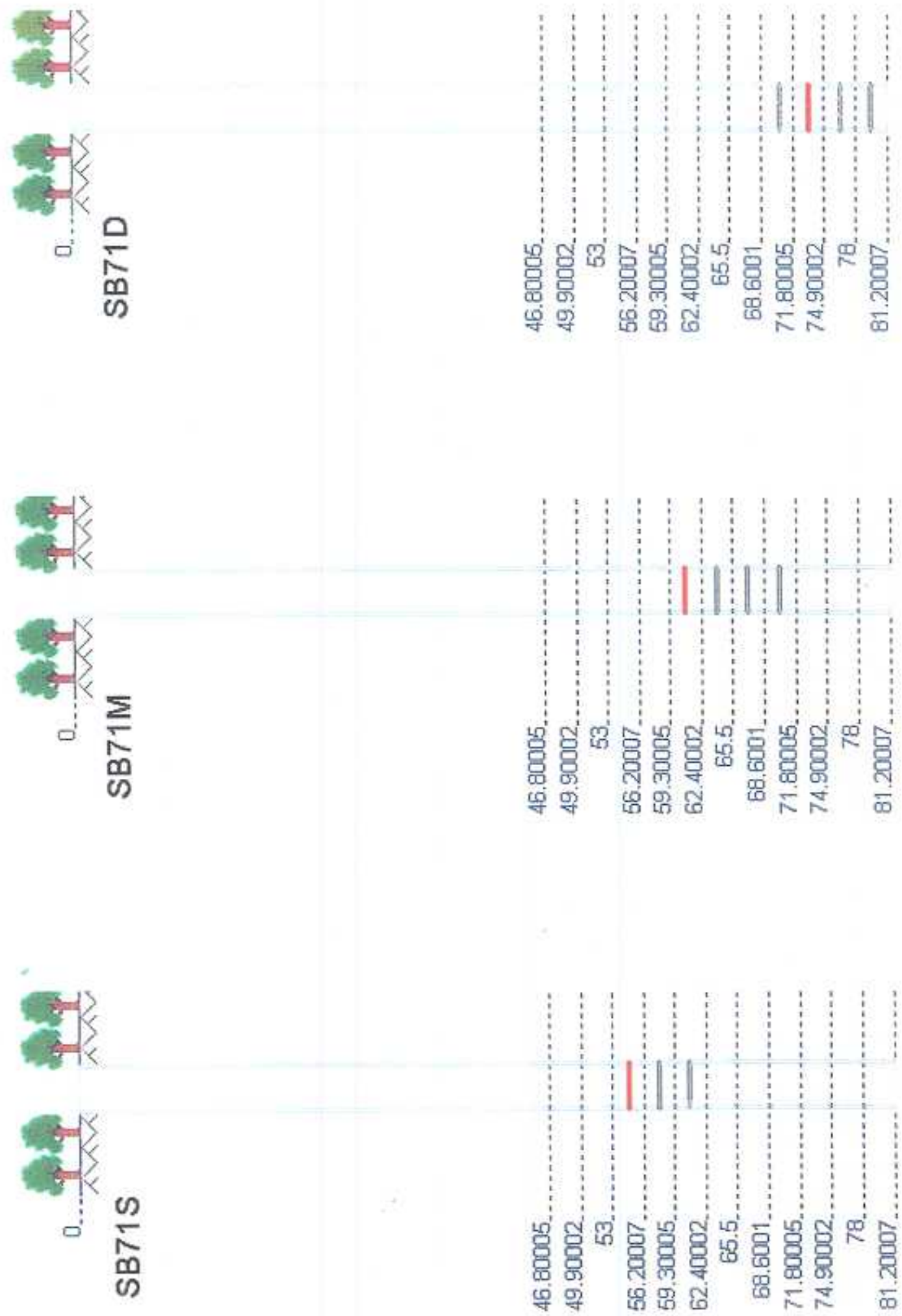


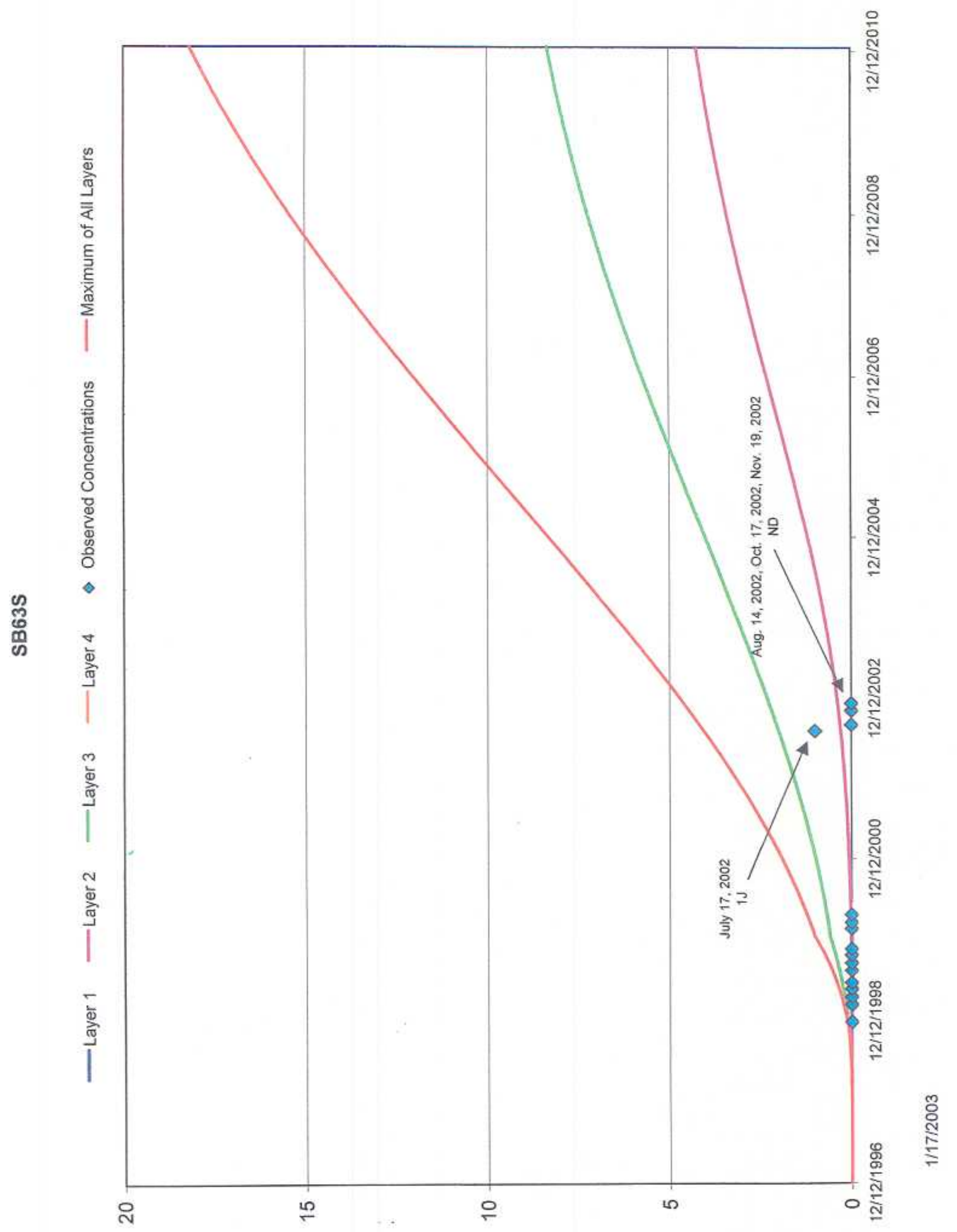




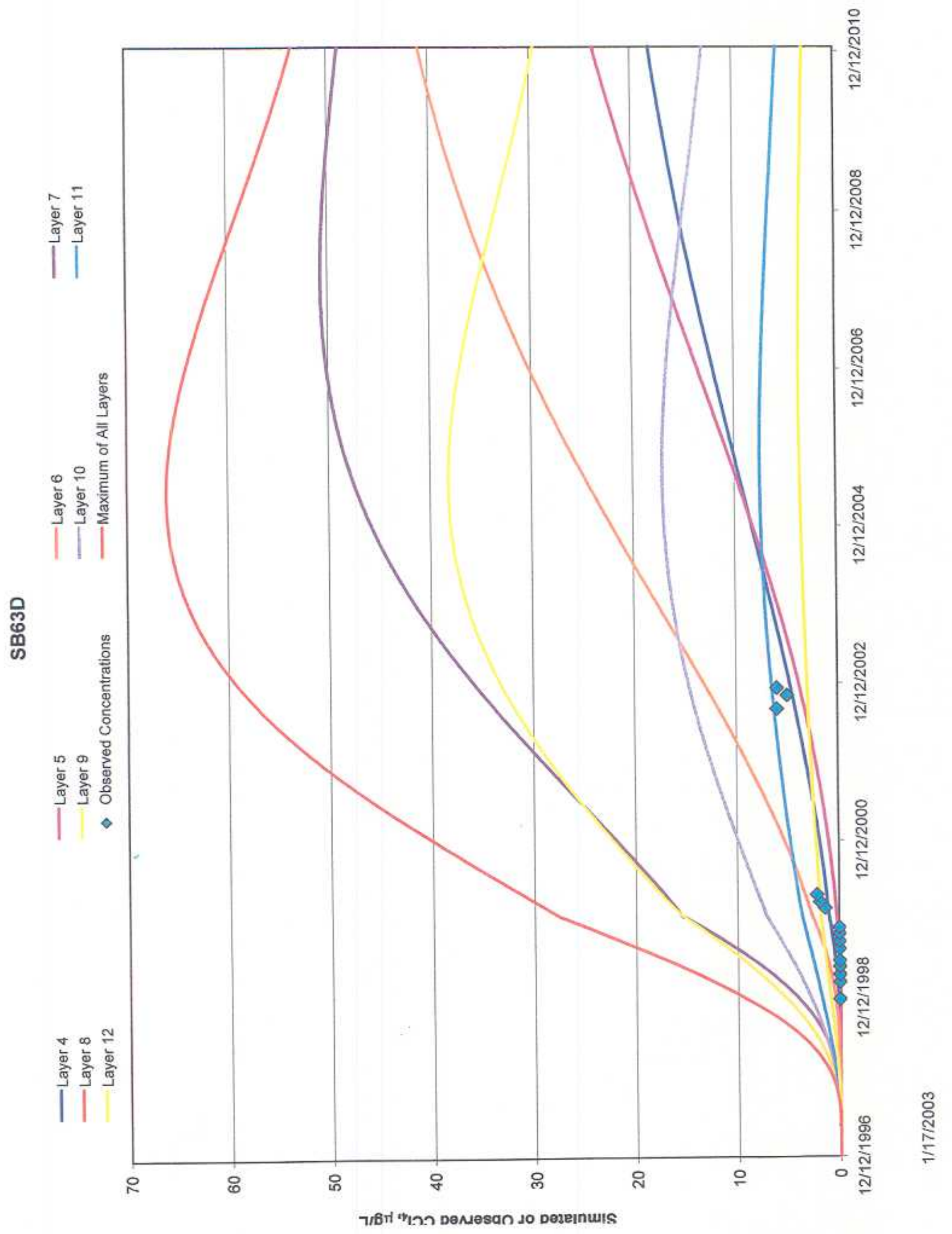




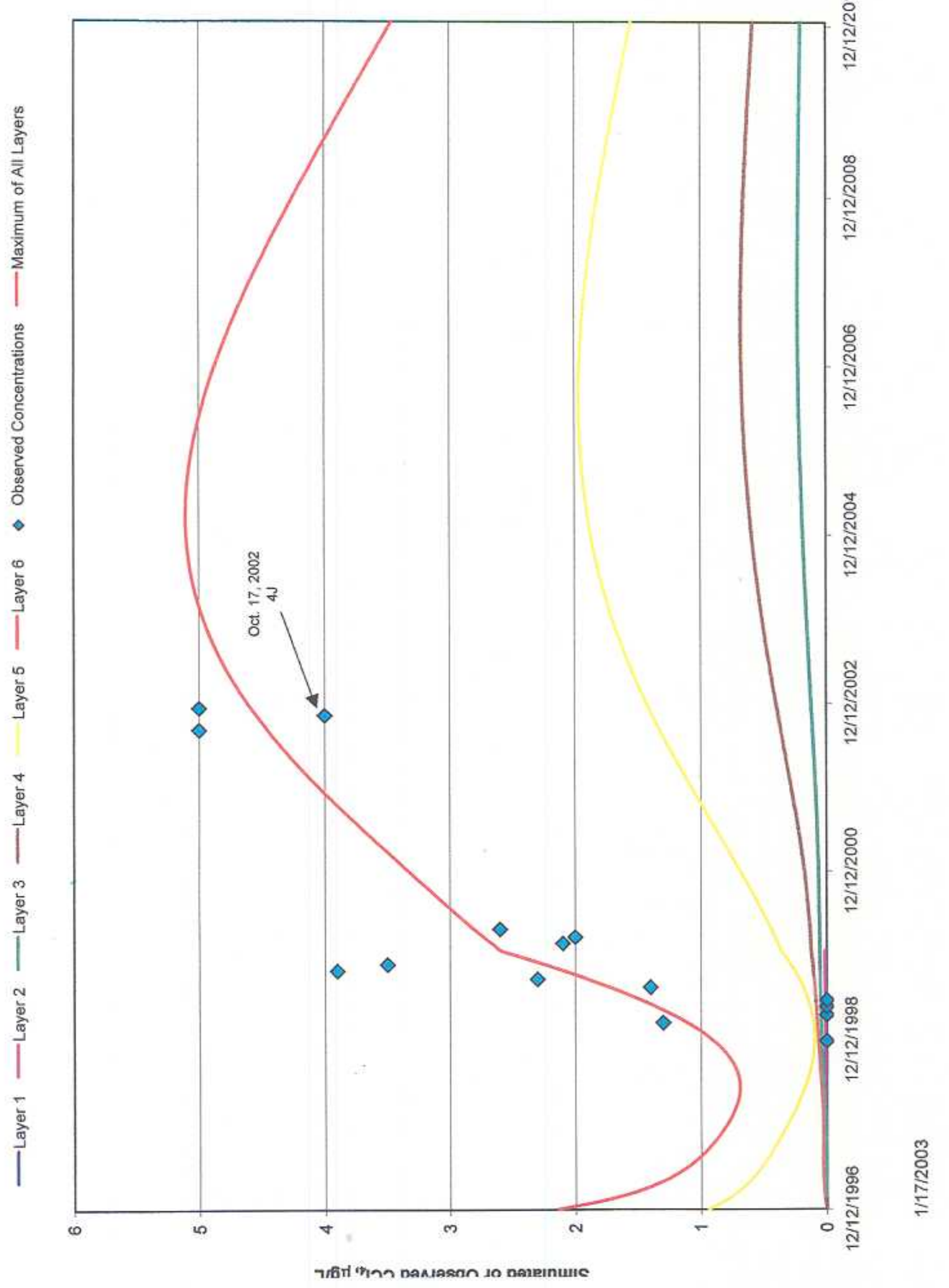




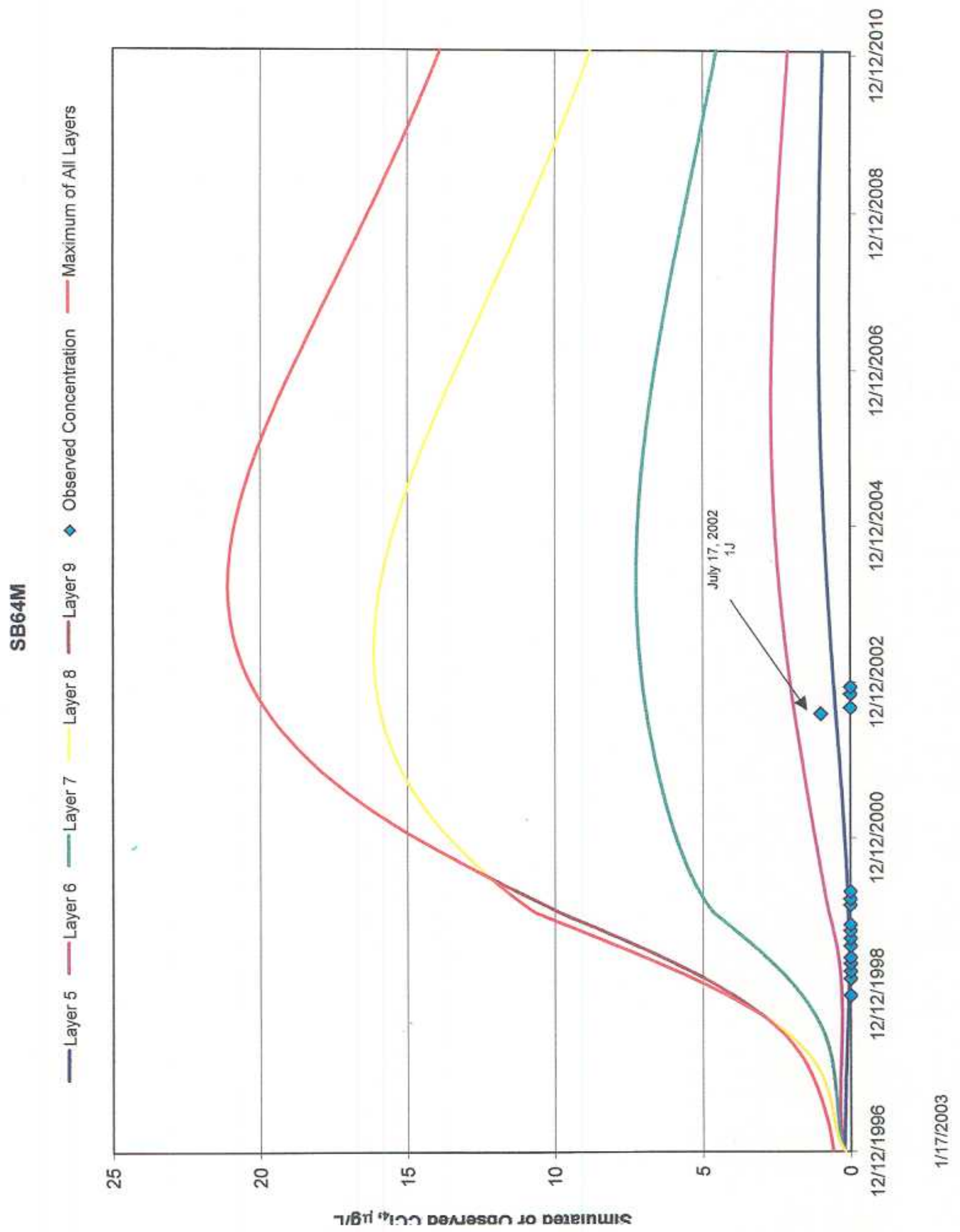




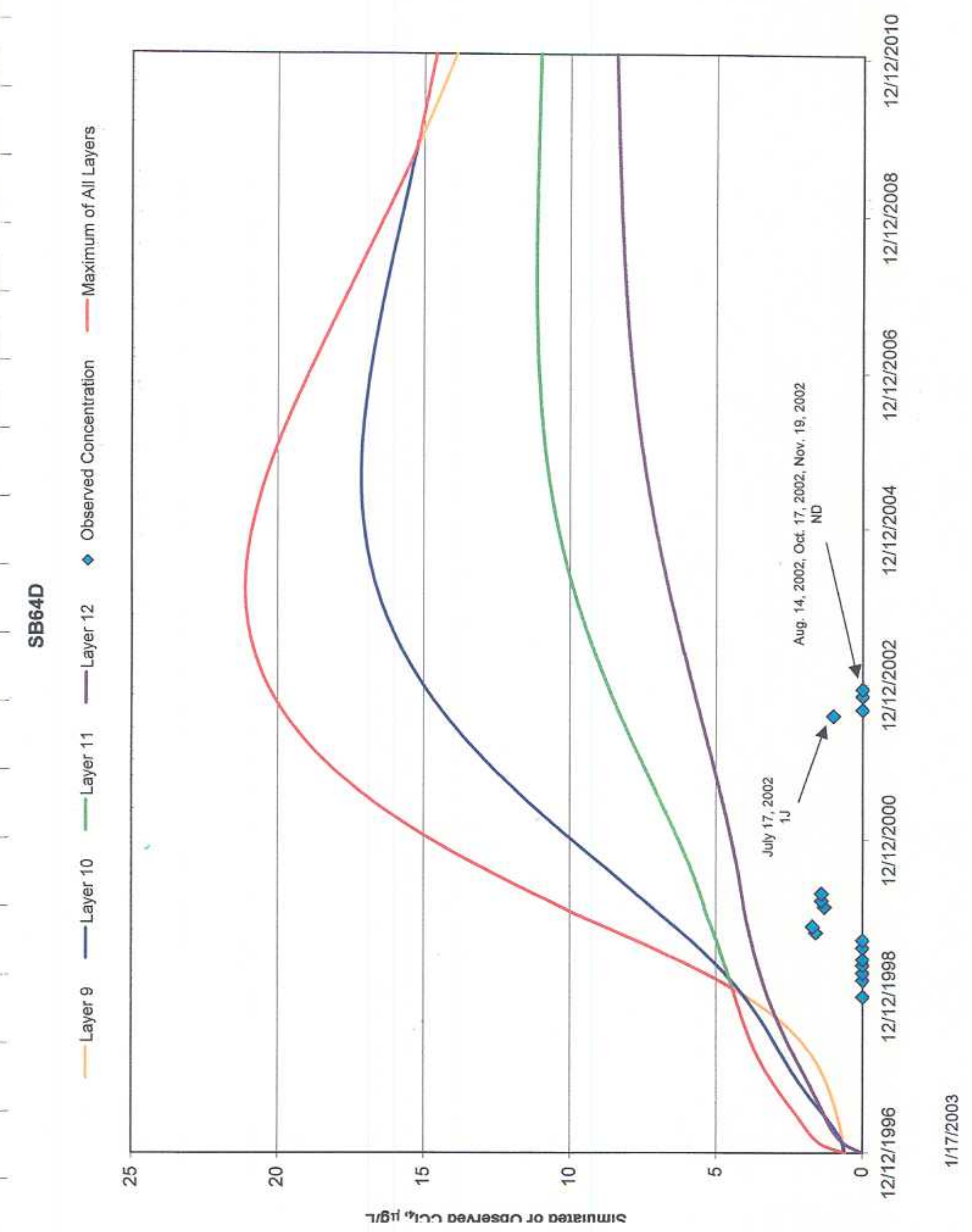




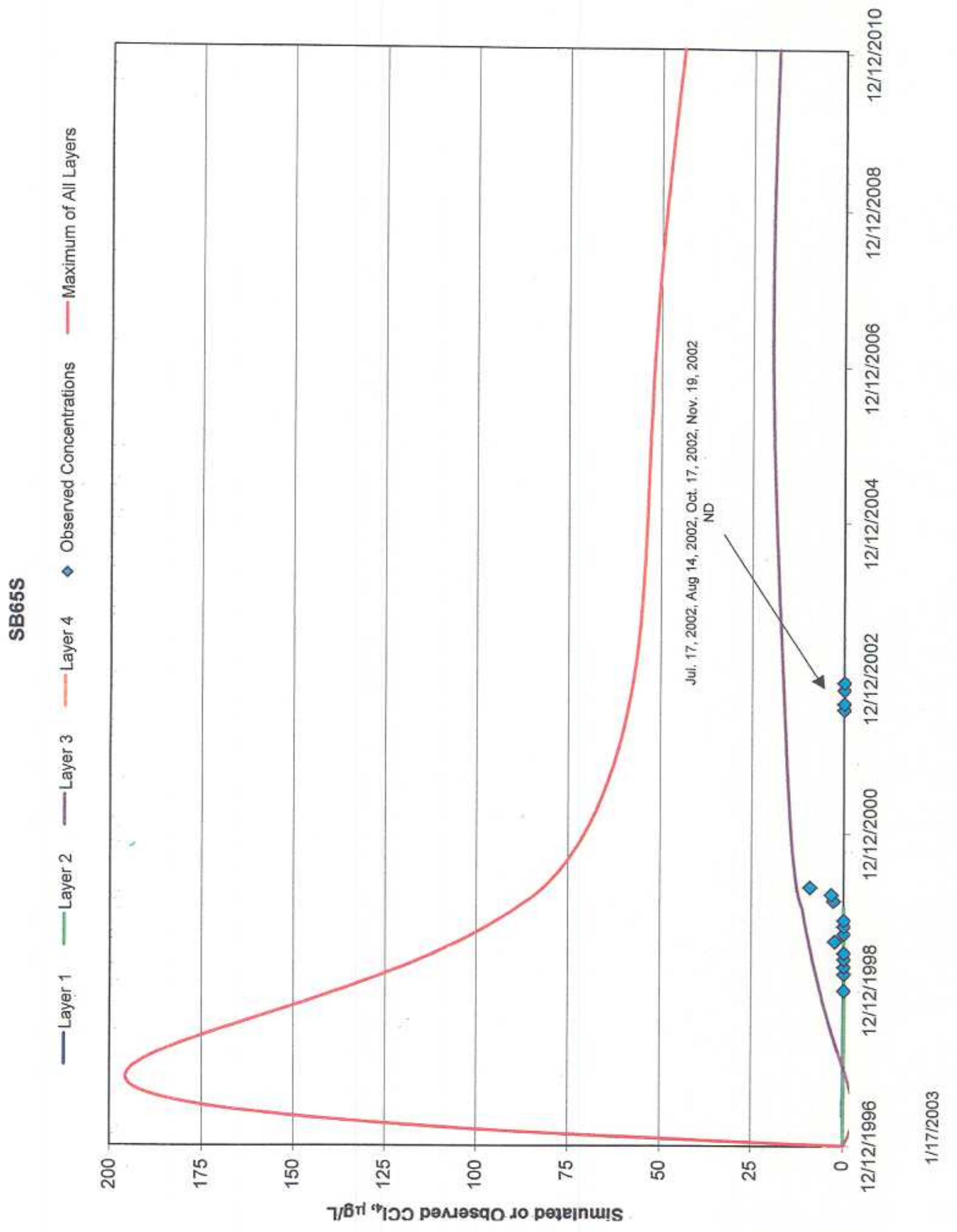




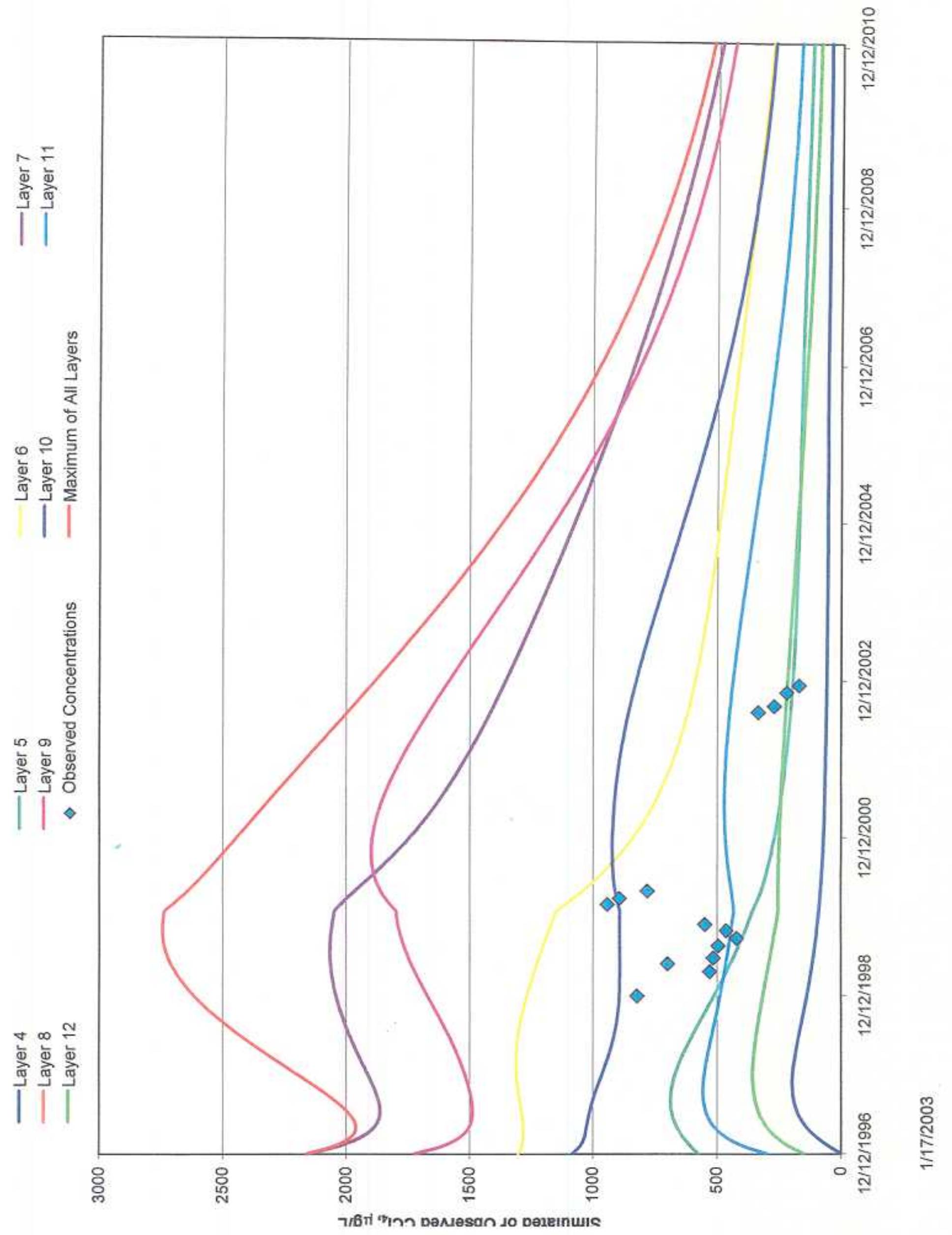


这

这

:

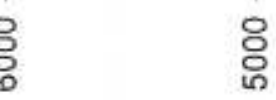

8

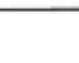




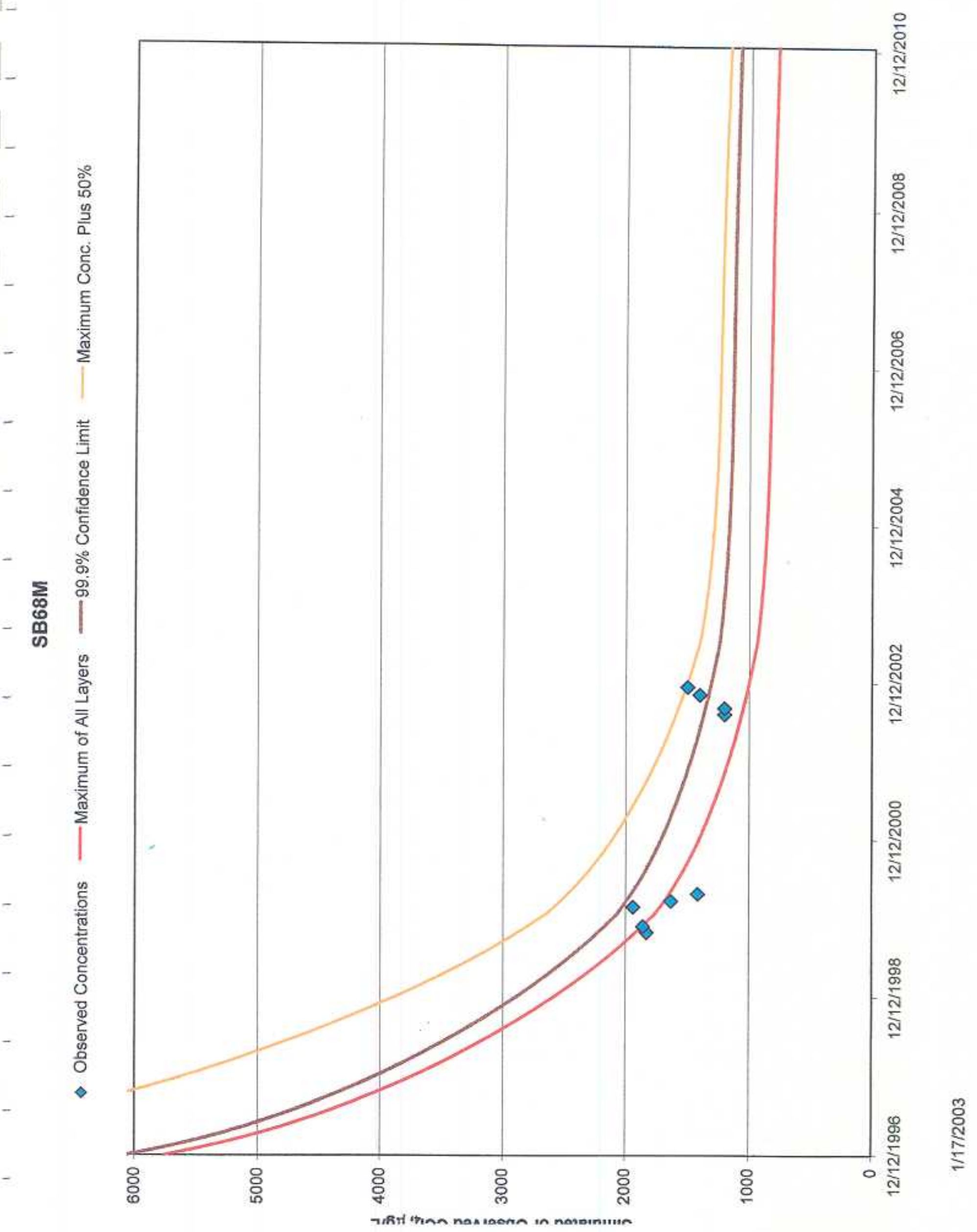




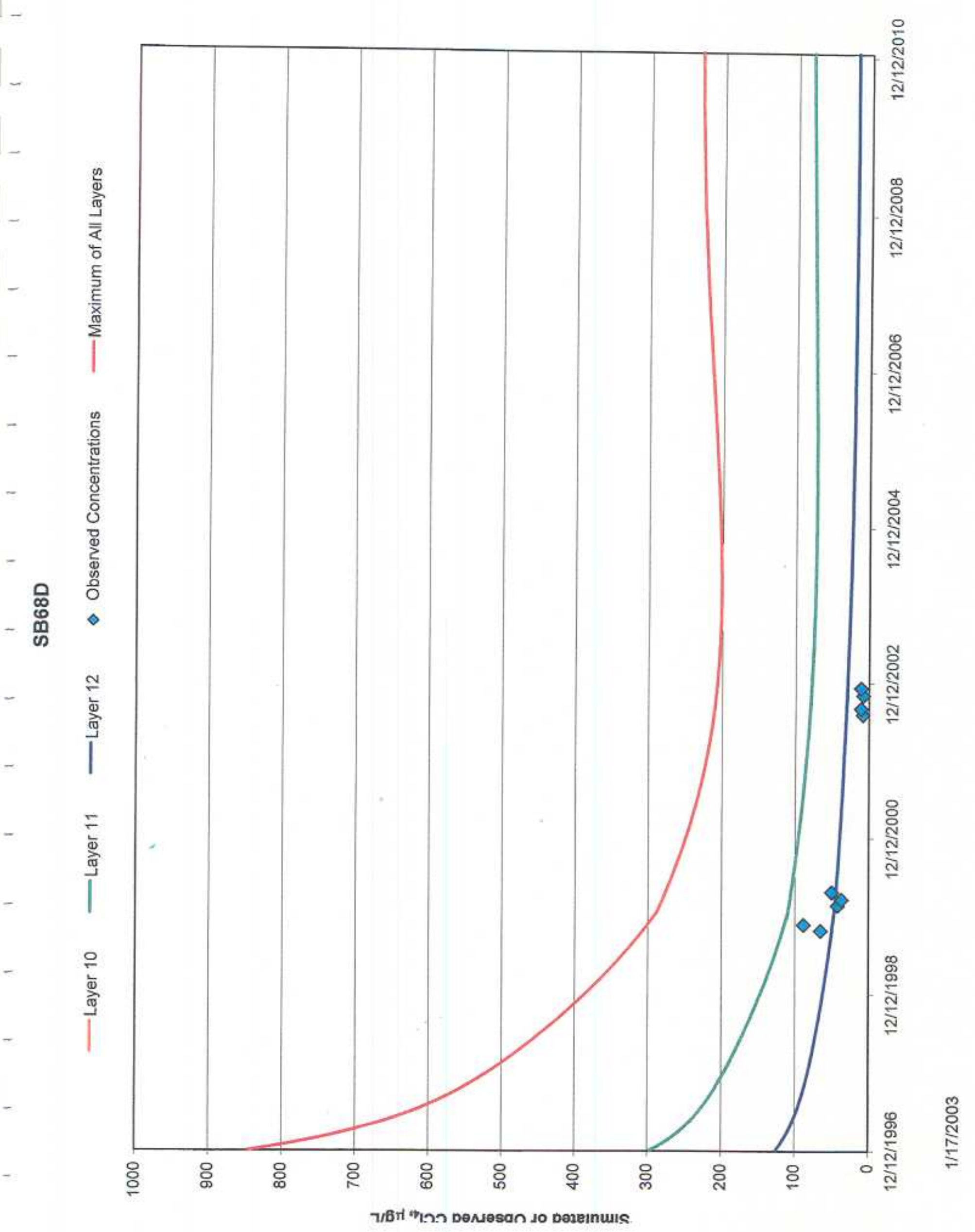




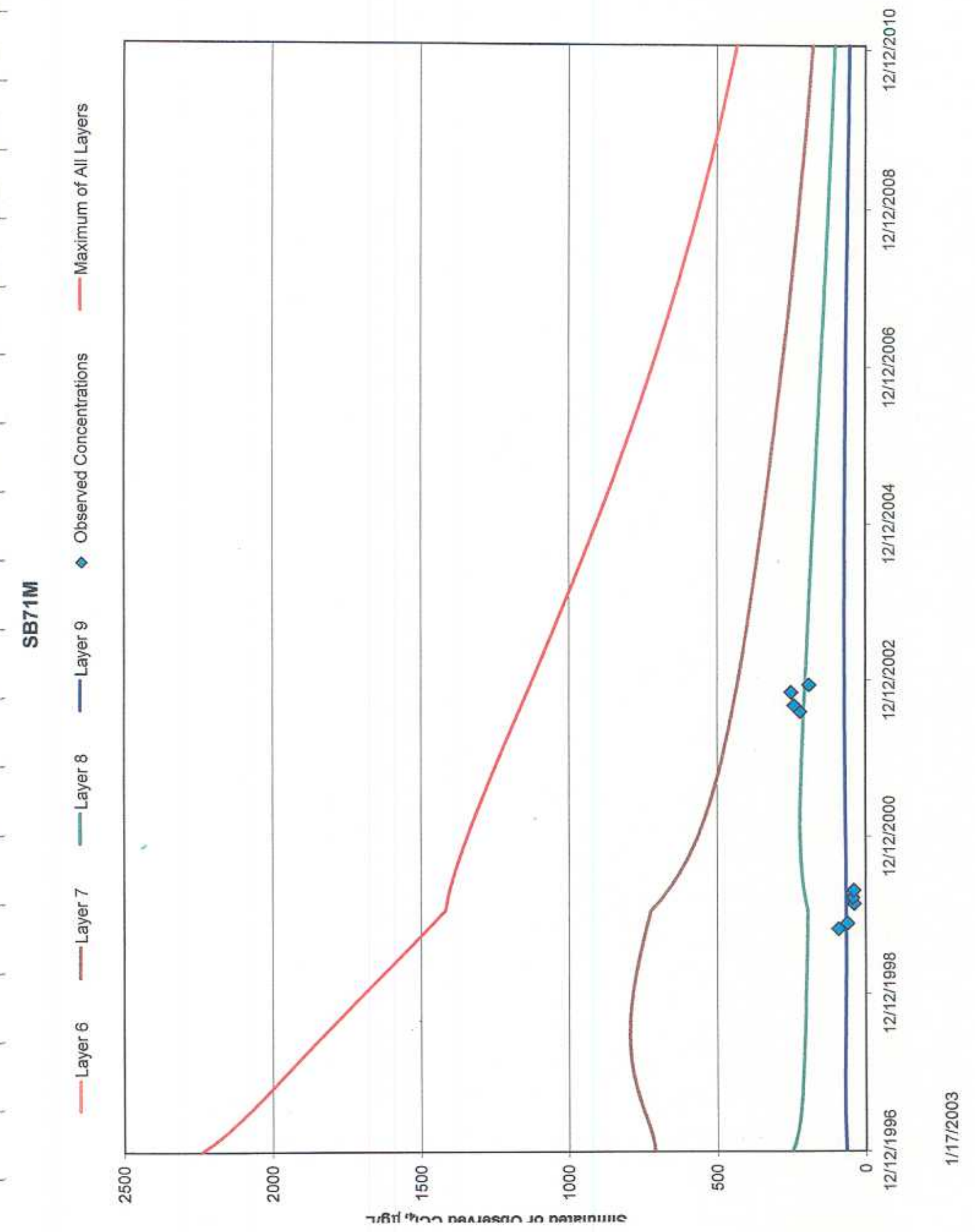




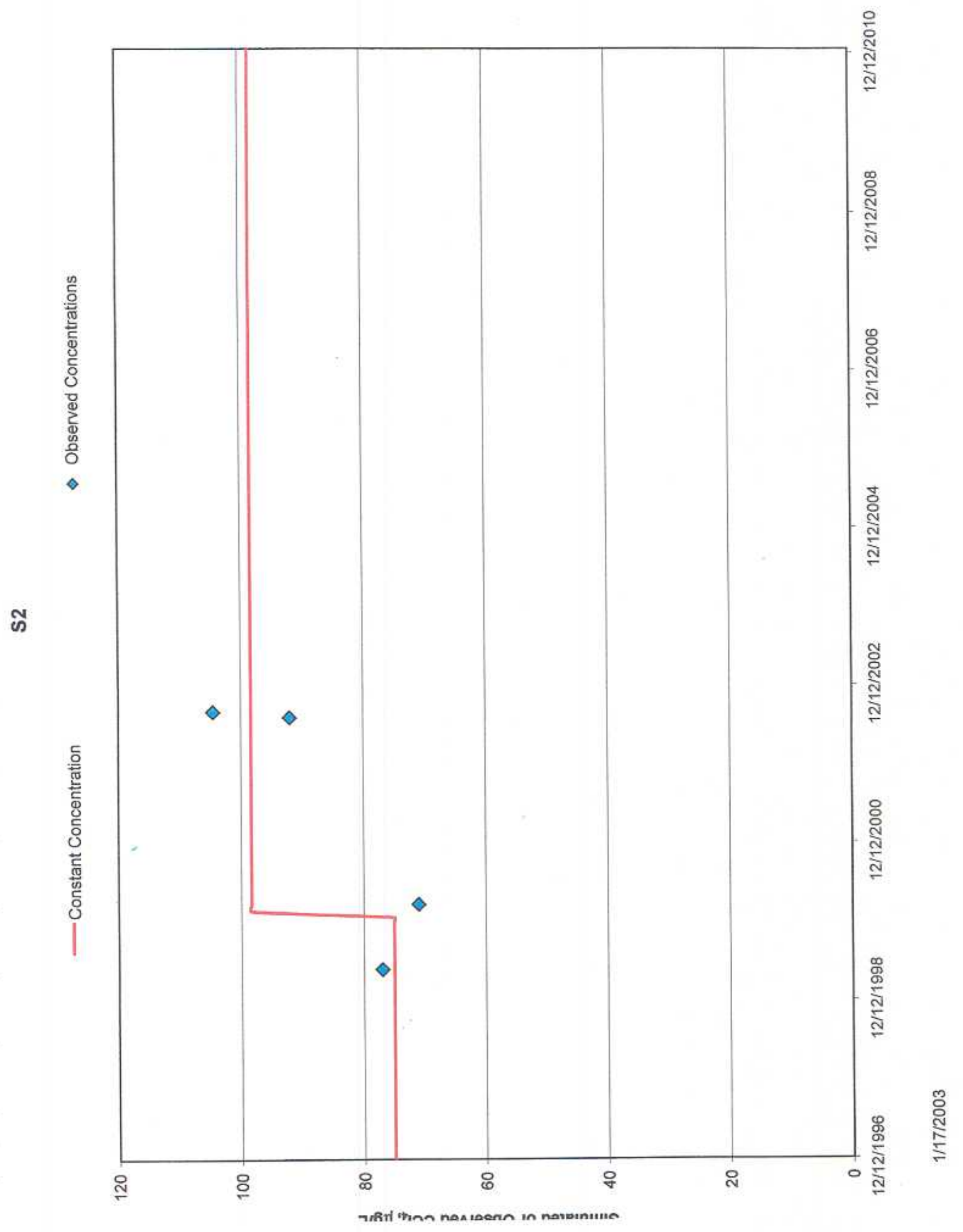




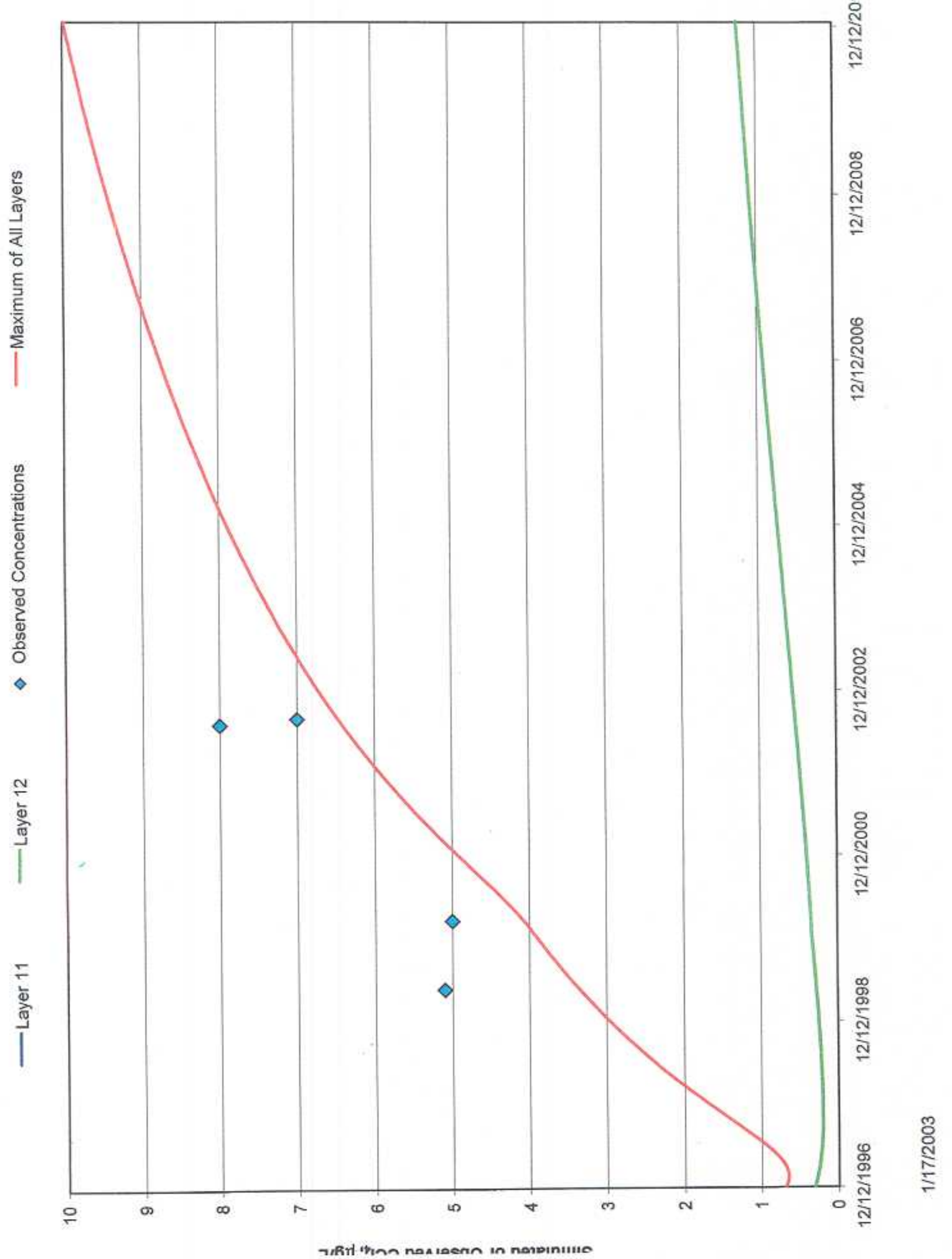




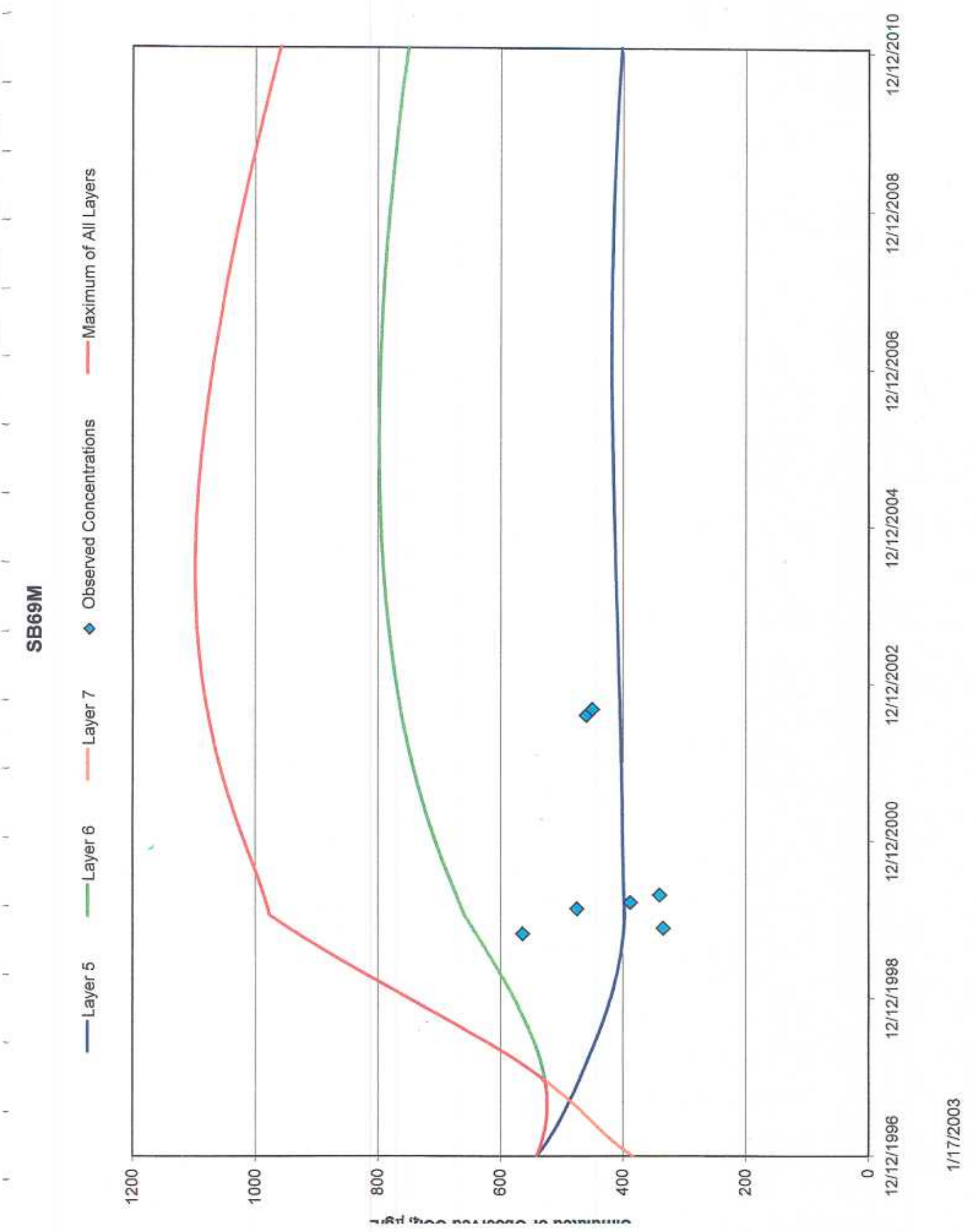




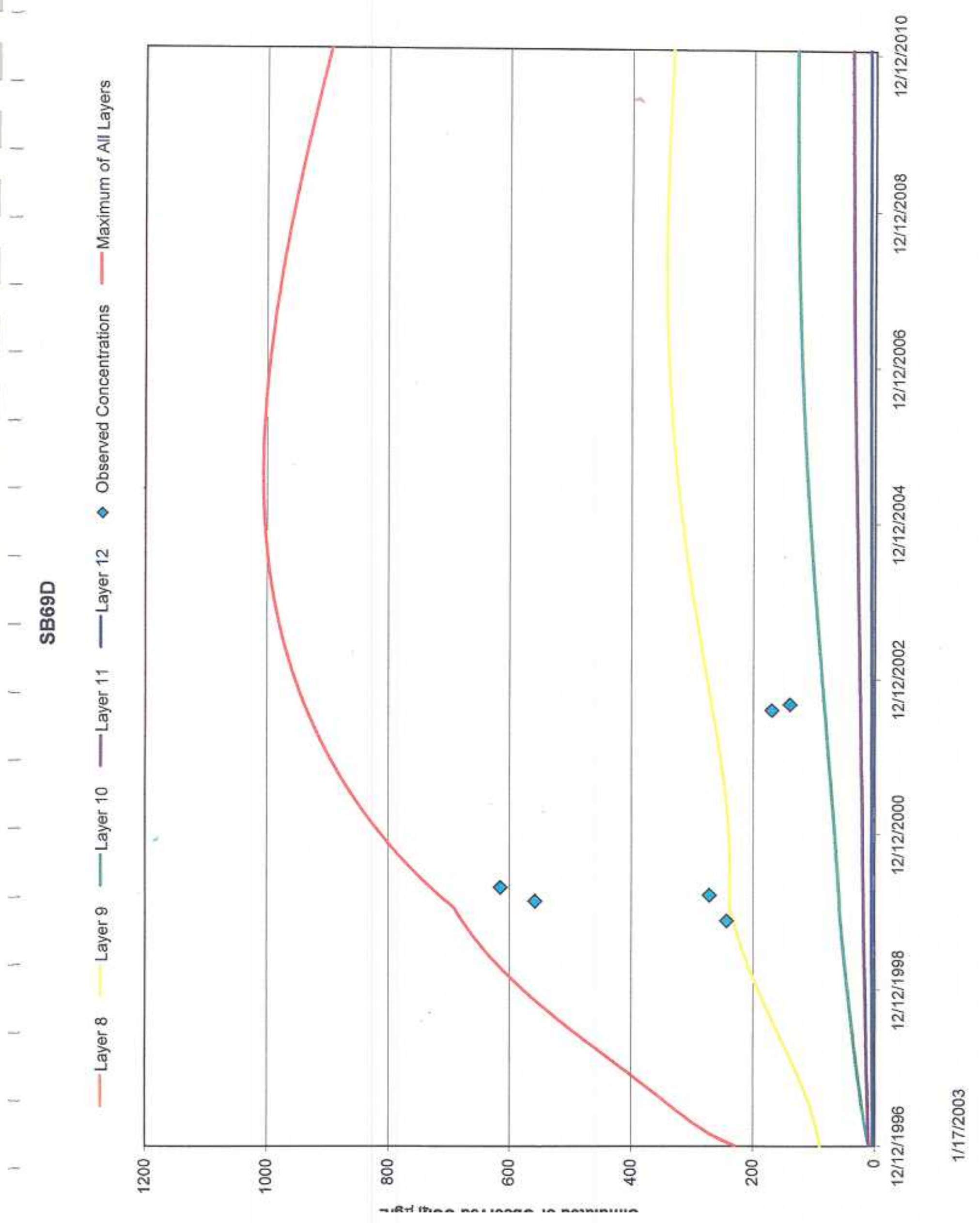




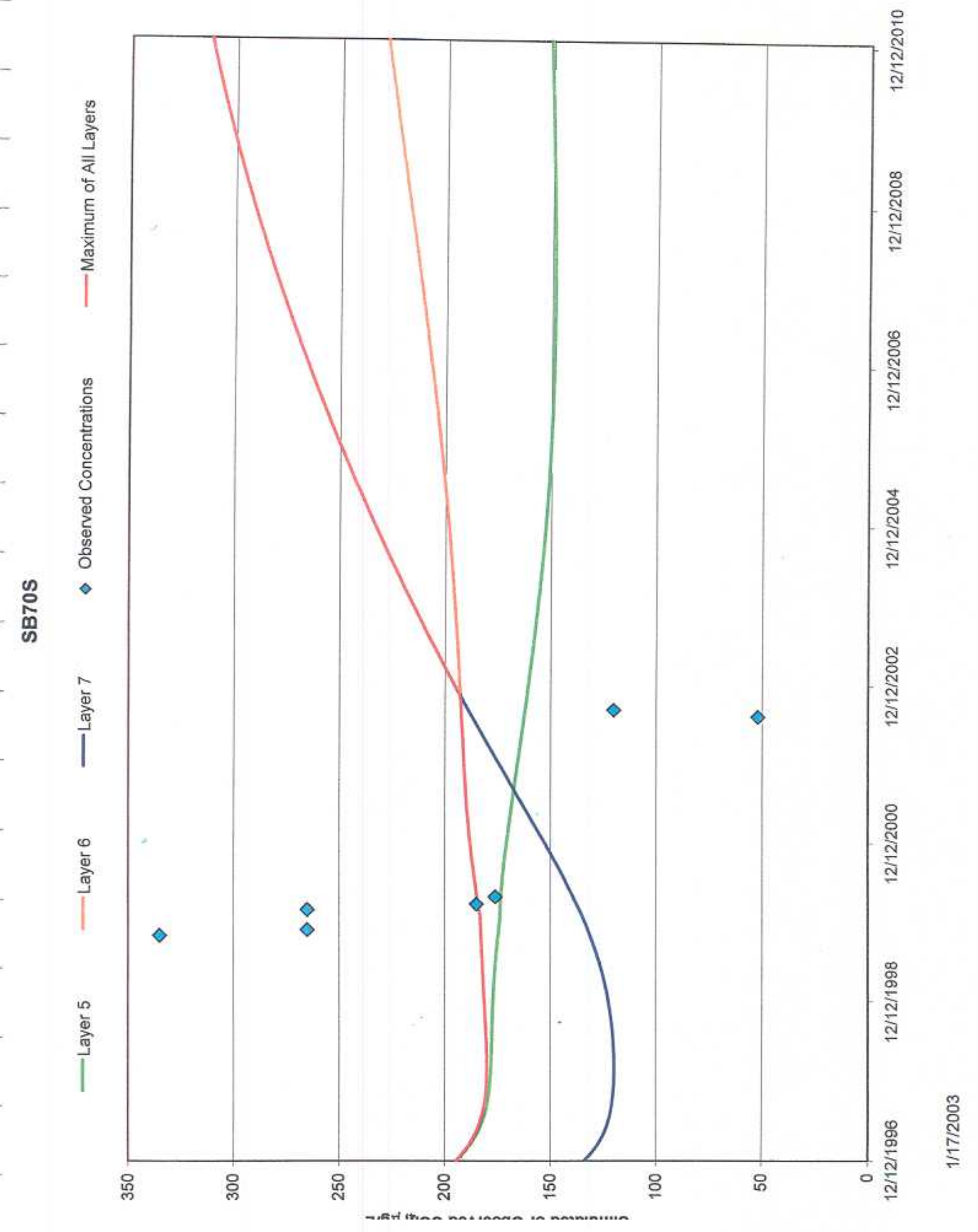




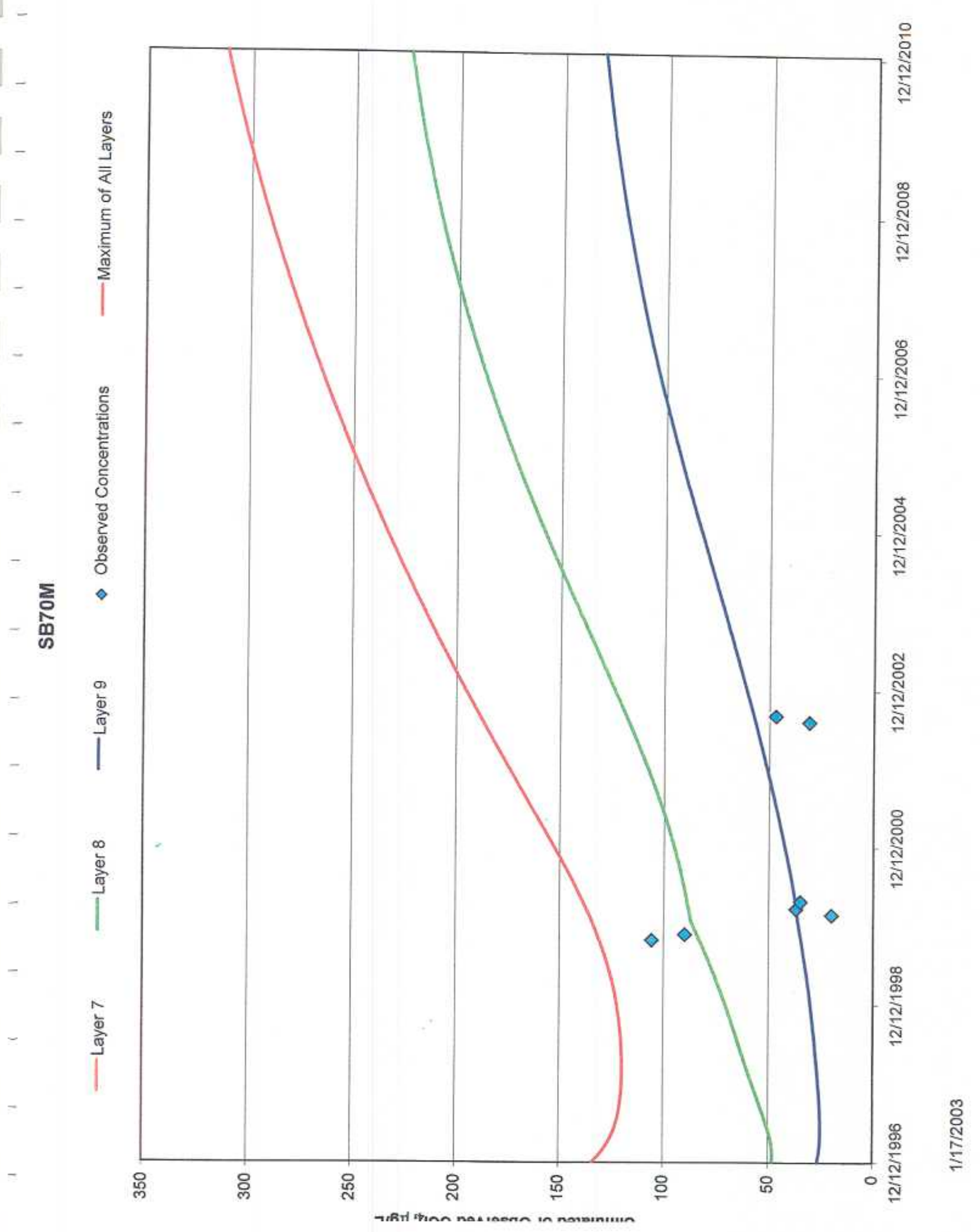




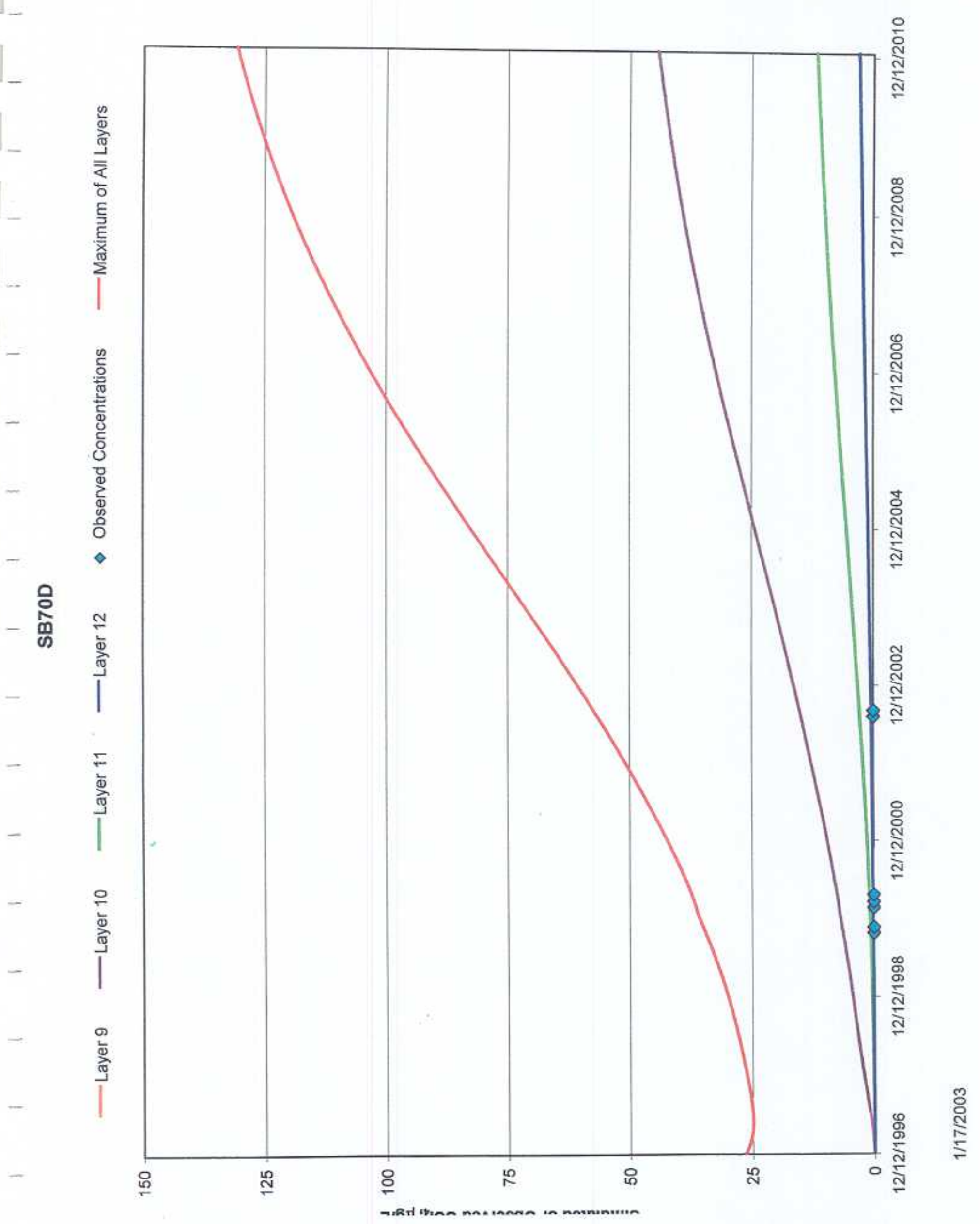




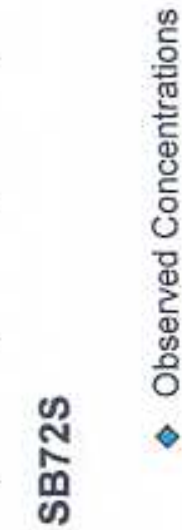

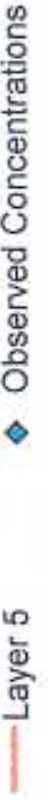

$\frac{4}{10}$

高

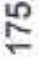

ัำ

8

욱

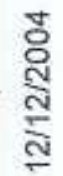

ัํำ

오․
సิ

을
సิ

+




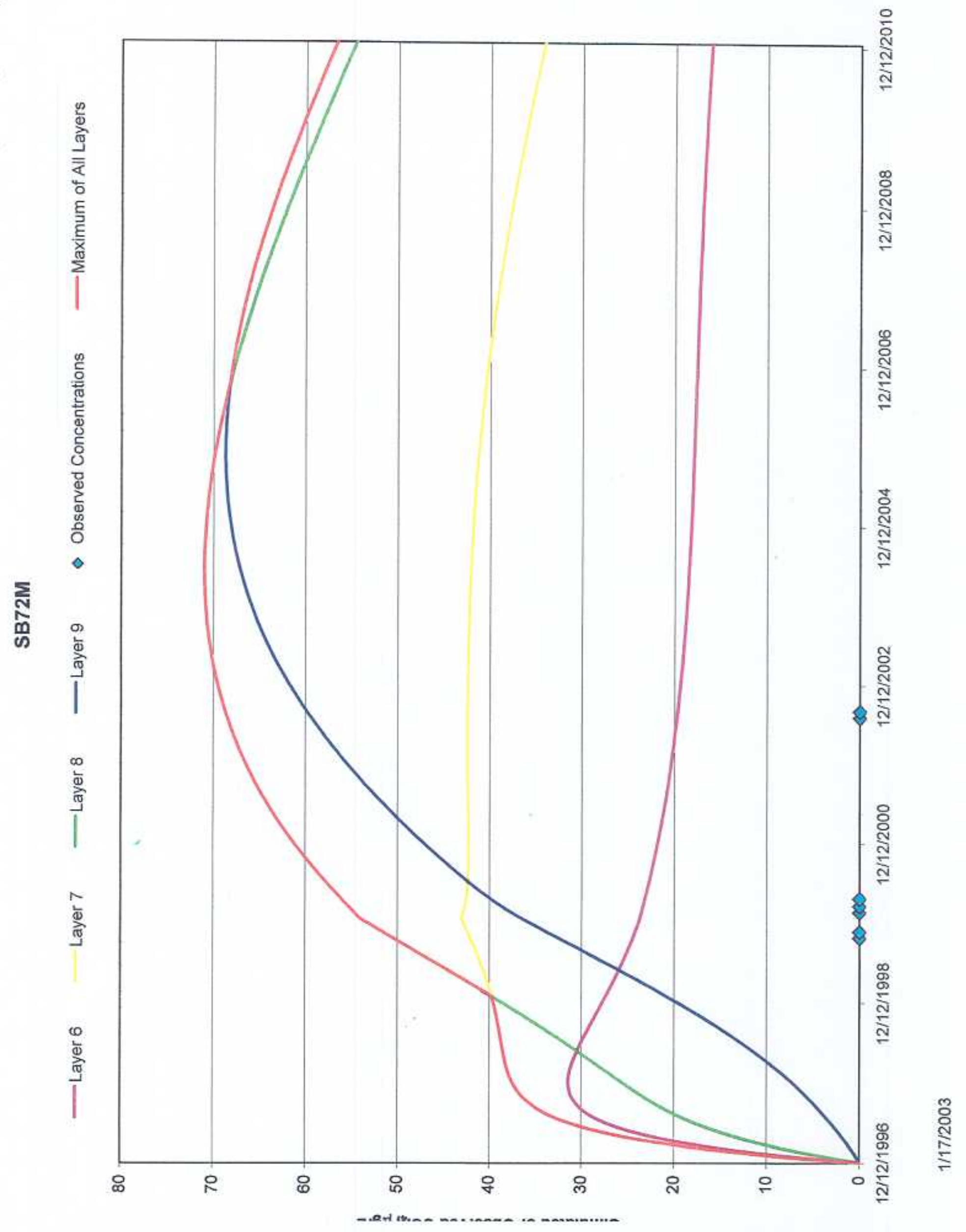




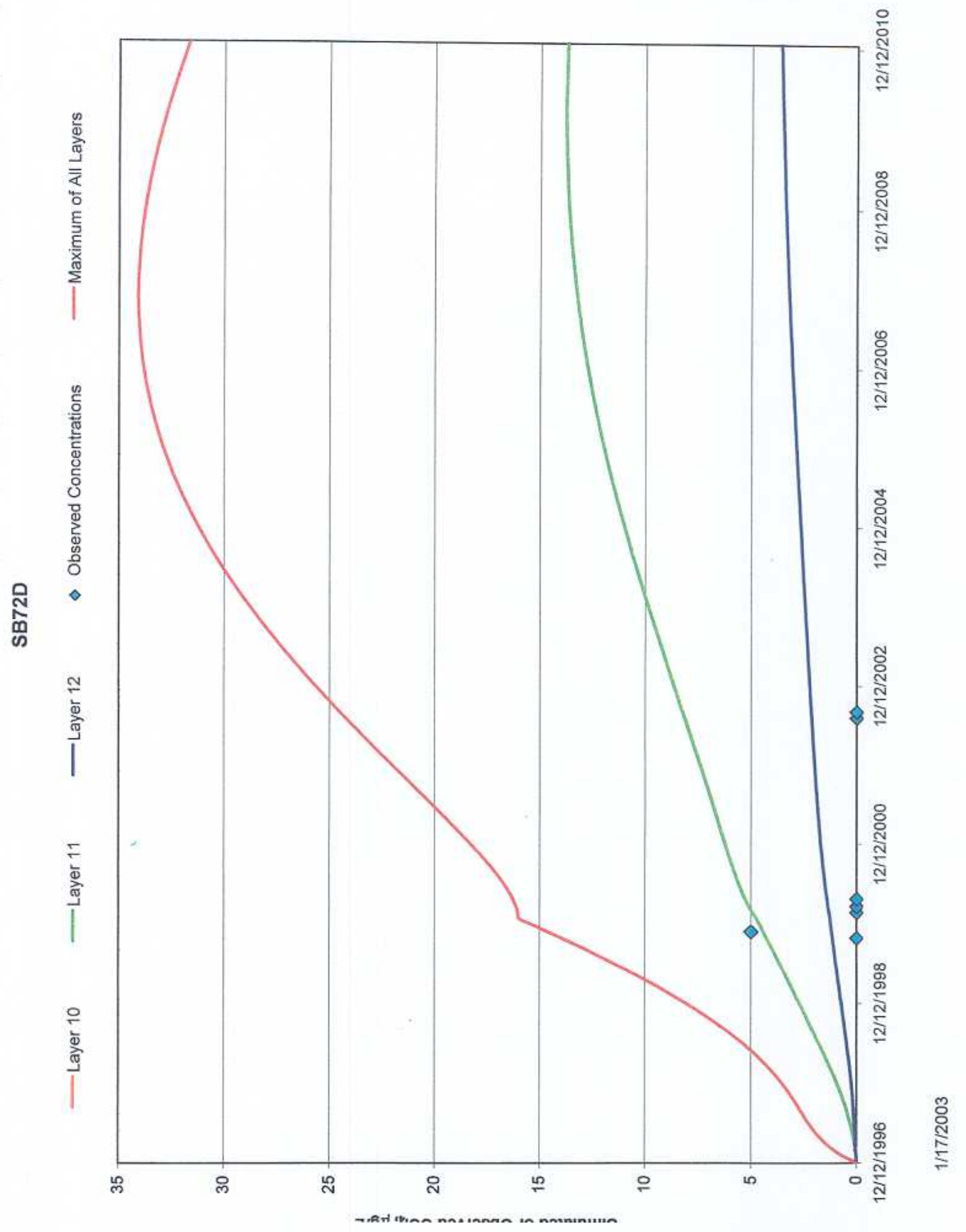

